\title{
WestVirginiaUniversity
}

THE RESEARCH REPOSITORY @ WVU

Graduate Theses, Dissertations, and Problem Reports

2020

\section{Chlordiazepoxide Increases Risky Choice}

Devin Andrew Galdieri

dag0018@mix.wvu.edu

Follow this and additional works at: https://researchrepository.wvu.edu/etd

Part of the Experimental Analysis of Behavior Commons

\section{Recommended Citation}

Galdieri, Devin Andrew, "Chlordiazepoxide Increases Risky Choice" (2020). Graduate Theses,

Dissertations, and Problem Reports. 7883.

https://researchrepository.wvu.edu/etd/7883

This Dissertation is protected by copyright and/or related rights. It has been brought to you by the The Research Repository @ WVU with permission from the rights-holder(s). You are free to use this Dissertation in any way that is permitted by the copyright and related rights legislation that applies to your use. For other uses you must obtain permission from the rights-holder(s) directly, unless additional rights are indicated by a Creative Commons license in the record and/ or on the work itself. This Dissertation has been accepted for inclusion in WVU Graduate Theses, Dissertations, and Problem Reports collection by an authorized administrator of The Research Repository @ WVU.

For more information, please contact researchrepository@mail.wvu.edu. 
Graduate Theses, Dissertations, and Problem Reports

2020

Chlordiazepoxide Increases Risky Choice

Devin Andrew Galdieri

Follow this and additional works at: https://researchrepository.wvu.edu/etd

Part of the Experimental Analysis of Behavior Commons 
Chlordiazepoxide Increases Risky Choice

Devin Andrew Galdieri

Dissertation submitted

to the Eberly College

at West Virginia University

in partial fulfillment of the requirements for the degree of

Doctor of Philosophy in

Psychology, Behavior Analysis

Karen G. Anderson, Ph.D., Chair

Barry Edelstein, Ph.D.,

Brad Humphreys, Ph.D.

Claire St. Peter, Ph.D.

Constance Toffle, Ph.D.

Department of Psychology

Morgantown, West Virginia

2020

Keywords: Chlordiazepoxide, benzodiazepine, risky choice, impulsivity, probability discounting Copyright 2020 Devin Galdieri 


\section{ABSTRACT \\ Chlordiazepoxide Increases Risky Choice}

Devin Andrew Galdieri

Probability discounting is a measure of risky choice that is correlated with maladaptive behavior and psychological disorders. Benzodiazepines are a class of drug on which relatively little riskychoice research has been conducted, particularly under conditions of chronic drug exposure. Chlordiazepoxide, a standard benzodiazepine, was administered to rats that had been trained to respond on a risky-choice task in which a choice was available between a single food pellet with $100 \%$ certainty or three food pellets with probabilities of delivery that decreased across each experimental session. During baseline, responding was sensitive to the programmed contingencies and larger-reinforcer choice decreased as the probability of delivery decreased. Acute administration of chlordiazepoxide dose-dependently increased risky choice. Tolerance to chlordiazepoxide's effects on larger-reinforcer-choice was observed after chronic drug exposure. The results of the present study indicate that acute chlordiazepoxide can increase risky choice in a probability-discounting task and that tolerance to this effect develops after chronic exposure to the drug. Limitations of the probability-discounting task and its relation to the hypothetical construct "risky choice" are discussed, as are suggestions for additional pharmacological targets and procedural variations for future studies on benzodiazepines, the GABA system, and risky choice. 


\section{ACKNOWLEDGEMENTS}

I would like to thank Dr. Karen Anderson, Dr. Barry Edelstein Carroll, Dr. Brad Humphreys, Dr. Constance Toffle, and Dr. Claire St. Peter for their time, guidance and feedback as members of my dissertation committee. I am sincerely grateful for all of the mentorship, training, and support that Dr. Karen Anderson, my advisor, has provided throughout my graduate career. I would like to acknowledge the training that I have received from all of the excellent faculty at West Virginia University and I would also like to thank my colleagues Jenny Ozga-Hess, Matt Eckard, Katya Nolder, Rebecca Chalmé for training me in the lab, helping me with experiments and lab work, and generally being wonderful lab-mates. Thank you, as well, to my mother and father, Janis Cross and Michael Galdieri, for their unconditional love and support. Last but not least, thank you to all of my friends in West Virginia, California, and everywhere else, for keeping me sane and motivated: Ashlee Gresham, Natalie Jones, Kristine Durkin, Mason Russell, Nick Felicione, Nick Hess, Jacob Solomon, Hannah Jones-Ozanian, Jesse Ozanian, Charles Curtis, and Edward Weaver. 


\section{TABLE OF CONTENTS}

Page

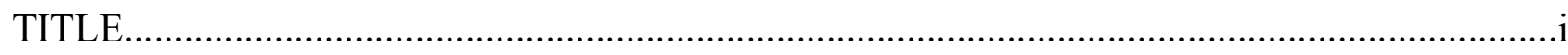

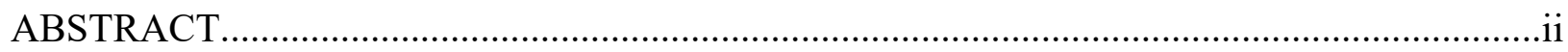

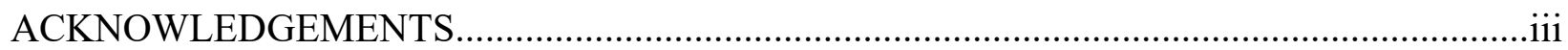

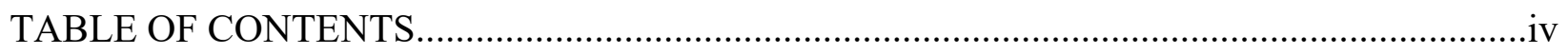

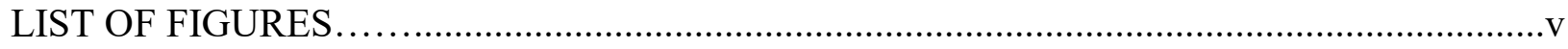

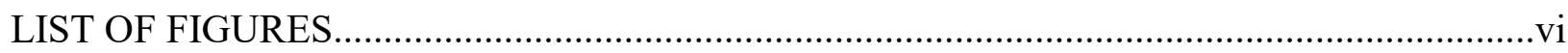

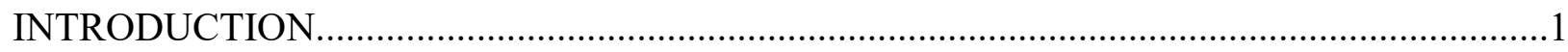

METHOD

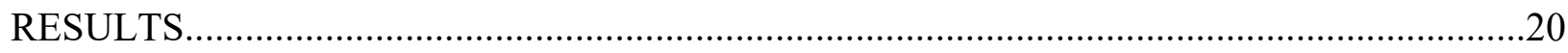

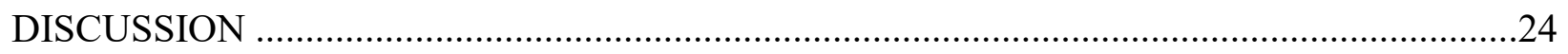

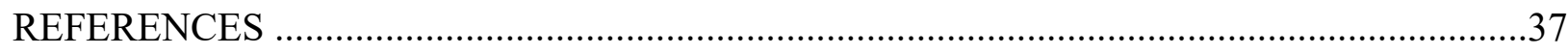

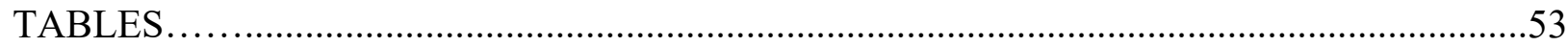

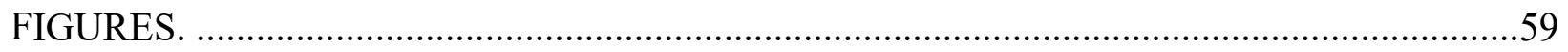




\section{LIST OF TABLES}

Table 1

.50

Mean and SEM for omitted trials at each dose of CDP in each phase.

Table 2 .

Mean and SEM for acute percent larger-reinforcer choice in each block during acute drug exposure.

Table 3. .52

Mean and SEM for area-under-the-curve (AUC), indifference points (IPs), win:stay ratios (WSRs) and lose:shift ratios (LSRs) during acute drug exposure.

Table 4 .53

Mean and SEM for percent larger-reinforcer choice (\% LRC), area-under-the-curve (AUC), indifference points (IPs), win:stay ratios (WSRs) and lose:shift ratios (LSRs) during the first and last five days of chronic exposure.

Table 5

Mean and SEM for percent larger-reinforcer choice in each block at each dose of CDP during chronic drug exposure.

Table 6. 55

Mean and SEM for area under the curve (AUC), indifference points (IPs), win:stay ratios

(WSRs), and lose:shift ratios (LSRs) at each dose of CDP during chronic drug exposure. 


\section{LIST OF FIGURES}

Figure 1

Group means and SEM for percent larger-reinforcer choice as a function of probability of delivery during acute drug exposure.

Figure 2

Individual means and SEM for percent larger-reinforcer choice as a function of probability of delivery during acute drug exposure.

Figure 3

Means and SEM for overall (full session) percent larger-reinforcer choice as a function of dose during acute drug exposure.

Figure 4

Means and SEM for area under the curve as a function of dose during acute drug exposure.

Figure 5

Mean and SEM for percent larger-reinforcer choice as a function of probability of delivery for acute saline, first five days of initial chronic drug exposure, and last five days of initial chronic drug exposure.

Figure 6

Mean and SEM for indifference points during the first and last five days of chronic drug exposure, as well as for baseline saline.

Figure 7 .62

Means and SEM for area under the curve during the first and last five days of chronic drug exposure, as well as for baseline saline. 
Figure 8

Means and SEM for win:stay ratios and lose:shift ratios during the first and last five days of chronic drug exposure, as well as for baseline saline.

Figure 9

Group means and SEM for percent larger-reinforcer choice as a function of probability of delivery during chronic drug exposure.

Figure 10

Means and SEM for percent larger-reinforcer choice as a function of probability of delivery for individual rats during chronic drug exposure.

Figure 11 66

Means and SEM for area under the curve as a function of dose during chronic drug exposure.

Figure 12

Means and SEM for indifference points as a function of dose during chronic drug exposure.

Figure 13 .68

Means and SEM for percent larger-reinforcer choice under saline during acute and chronic drug exposure. 


\section{Chlordiazepoxide Increases Risky Choice}

Maladaptive decision-making, a component of many psychiatric disorders and problematic behavior in general, can be divided into several categories. Risky choice is a category of maladaptive decision-making that can be conceptualized as preference for a larger, riskier reward over a smaller, certain reward. Risky choice can be measured using probabilitydiscounting procedures, which are supported by a broad literature base and can provide multiple measures that describe how risky choice changes as a function of environmental influences. One such environmental influence is pharmacological manipulation.

Many drugs have been shown to exert effects on risky choice in human and non-human animals as measured by probability-discounting procedures. Benzodiazepines are a class of drugs that have been shown to increase some forms of risky choice in humans and non-human animals, but little is known about how benzodiazepines affect probability discounting in humans or nonhuman animals. Benzodiazepines produce numerous effects on decision-making when administered acutely, and long-term use is associated with a similar but distinct set of effects. The present study was designed to examine effects of acute and chronic administration of a typical "gold-standard" benzodiazepine, chlordiazepoxide, in a well-established laboratory model of risky choice (i.e., a probability-discounting procedure).

\section{Risky Choice}

Maladaptive decision-making is a key feature of numerous psychiatric disorders, including attention-deficit/hyperactivity disorder (ADHD), gambling disorder, substance-use disorders, mood disorders, and primary psychotic disorders (Berry et al., 2019; Drechsler et al., 2010; Hart, Brown et al., 2019; Hayashi et al., 2018; Kyonka \& Schutte, 2018; Moreira et al., 2019; Shurman et al., 2005). Maladaptive decision-making is also associated with risky sexual 
practices, increased drug use, texting while driving, and other high-risk behavior (Chuang et al., 2017; Dir et al., 2014; Hayashi et al., 2016). Contemporary accounts of maladaptive decisionmaking often discuss separate forms of maladaptive decision-making. Excessive devaluation of delayed rewards (delay discounting) or suboptimal valuation of uncertain outcomes (probability discounting) are two commonly discussed forms of maladaptive decision-making. When maladaptive decision-making occurs in relation to uncertain outcomes, it is referred to as risky choice.

Risky choice can be conceptualized as preference for a larger reward that is associated with some probability of an adverse outcome instead of a smaller reward with no probability of an adverse outcome. An adverse outcome may come in the form of a smaller reward, a lack of reward altogether, a time-out from earning rewards, and/or the addition of an aversive stimulus. For example, choosing to speed on the freeway in order to get to a destination quickly instead of driving the speed limit and arriving later could be a risky choice. There is increased probability of a receiving a speeding ticket when speeding (and subsequently arriving late), but also a greater and more likely potential reward (e.g., less time spent driving, arriving sooner).

Often, it is advantageous to discount the value of an outcome when it is relatively unlikely. For example, many people take the risk of driving on the freeway every day to get to work because the risk of being involved in an automobile accident is relatively low, and the rewards associated with going to work are relatively high. However, most people choose not to speed on the freeway while heading to work. In this scenario, the potential to arrive at work a few minutes early does not outweigh the potential consequences of a citation and/or collision.

In either case, risky choice can be related to risk aversion (some individuals may be less sensitive to risks) and/or reward sensitivity (some individuals may be more sensitive to rewards). 
Consider, for example, an individual with a gambling problem who continues to spend money even though it is extremely unlikely that such behavior will result in a net gain. Continued gambling could be due to an insensitivity to loss, or to an oversensitivity to reward. On the other hand, the individual could simply be ineffective at determining the relative value of probabilistic outcomes (i.e., the economic utility of continued gambling), regardless of their sensitivity to winning or losing. In an effort to study this phenomenon objectively, researchers have developed several pre-clinical models to assess risky choice.

Risky choice can be assessed experimentally with several procedures. Pre-clinical models include rat gambling tasks, the Balloon Analog Risk Task (BART), and probability-discounting procedures (e.g., Cardinal \& Howe, 2005; Hastjarjo et al., 1990; Jentsch et al., 2010; Winstanley \& Floresco, 2016; Zeeb et al., 2009). Rat gambling tasks typically involve a choice between responses that produce varying amounts of reward but are also associated with differing probabilities of non-reward in the form of time-out from earning rewards or no reward delivery. Similarly, the BART involves a choice between two responses. However, in the BART, one response increases the amount of reward available but also increases the likelihood that all of the accrued rewards will be erased (the BART takes its name from a hypothetical task in which an individual attempts to pump up a balloon as much as possible without popping it). The other response option in the BART allows for a "cash out" where the previously accrued reward amount is delivered. In essence, the BART involves the choice between a smaller reward with less risk and a larger reward with an increasing risk of loss.

Probability-discounting procedures involve a choice between two responses as well. Response options include a response that produces a smaller reward every time, and a response that produces a larger reward with some probability of non-delivery. The probability of the larger 
reward being delivered is manipulated (typically reduced) across trials, and the relative value of the larger reward is said to be discounted as a function of the probability of its non-delivery.

Probability-discounting procedures have several advantages over other measures of risky choice. First, there is a robust literature base in which probability-discounting procedures have been used to characterize group differences in risk-taking clinical subpopulations and healthy controls (e.g., Drechsler et al., 2010; Kyonka \& Schutte, 2018; Levy et al., 2019; Hart et al., 2019). This literature also includes experimental data regarding various environmental and pharmacological manipulations that alter probability discounting (e.g., Lane et al., 2008; Lane et al., 2005; St. Onge, et al., 2010; St. Onge \& Floresco, 2009). Second, probability-discounting procedures with non-human animals typically require minimal pre-training and produce longlasting stability in responding, which allows for risky choice to be analyzed over time (Galdieri, 2018; Ozga \& Anderson, 2018). Third, probability-discounting procedures share some features with the similar yet distinct phenomenon of delay discounting. Identifying similarities and differences in these distinct but related forms of maladaptive decision-making is a separate, ongoing area of research (for a review of similarities and differences, see Green \& Myerson, 2014). Finally, probability-discounting procedures produce several useful measures that allow multiple levels of analysis of choice.

There are at least five measures that can be obtained with probability-discounting procedures. Percent larger-reinforcer choice is the proportion of responses made for the larger, risky reward overall and at a given probability of delivery. Plotting percent larger-reinforcer choice as a function of decreasing probability of delivery yields a hyperboloid curve. Such a curve can be analyzed qualitatively via visual inspection and quantitatively by calculating the area under the curve (AUC). Indifference points (IPs) are calculated by interpolating the 
probability value at which responses for the larger, risky reward and the smaller, certain reward are equally likely. Increased percent larger-reinforcer choice (specifically at low probabilities of delivery), increased IPs, and increased AUC are all indicative of increased risky choice.

Trial-by-trial measures of responding can also be obtained by analyzing how responding changes following a non-reinforced response for the larger reinforcer (lose-shift ratio; LSR) and how responding persists following a reinforced response for the larger reinforcer (win-stay ratio; WSR). LSRs and WSRs are important because they reflect how responding is affected by recent extinction (lose-shift) and recent reinforcement (win-stay), and are differentially affected by environmental factors (Bari et al., 2010; Forder \& Dyson, 2016; Reed, 2018; Thapa \& Gruber, 2018; Stopper \& Floresco, 2011; Tom et al., 2007).

\section{Pharmacological Manipulation of Risky Choice}

One factor that affects risky choice in general is pharmacological manipulation. Drugs that have been shown to increase risky choice in probability-discounting experiments include dopaminergic drugs such as $d$-amphetamine and flupenthixol (e.g., St. Onge et al., 2010; St.

Onge \& Floresco, 2009). Noradrenergic drugs, such as dexmedetomidine and clonidine have been shown to reduce risky choice, while noradrenaline antagonists such as atomoxetine and reboxetine have produced mixed results, with some studies reporting increases, and others reporting no effect (Cui et al., 2018; Montes et al., 2015; Ozga \& Anderson, 2018). Several studies have found no effect of serotonergic manipulations on risky choice (Anderson, et al., 2003; Blaes et al., 2018; Mobini et al., 2000; Yang et al., 2016).

There is some evidence that gamma-aminobutyric acid (GABA) receptors, which are activated by ethanol and other drugs, play a role in risky choice. Results of some studies have shown that acute and chronic ethanol exposure can increase risky choice in probability- 
discounting and other procedures (Bidwell et al., 2013; Schindler et al., 2014; Wallin-Miller et al., 2017). However, little is known about how other pharmacological manipulations of the GABA system affect risky choice.

\section{Benzodiazepines and the GABA System}

Benzodiazepines are a class of drugs that activate the GABA system. Benzodiazepines are prescribed for short-term treatment of conditions such as anxiety, seizures, and alcohol withdrawal (Kaiser Permanente, 2019). In 2017, more than one-in-eight adults reported using benzodiazepines at least once, with misuse accounting for approximately $17 \%$ of all use (O’Neal, 2018). Between 2004 and 2010, emergency-department visits for benzodiazepine misuse increased 139\% (O’Neal). Admissions to benzodiazepine-abuse treatment programs nearly tripled between 1998 and 2008, although admissions to drug-abuse treatment programs overall increased by only 11\% (Schmitz, 2016). Benzodiazepine overdose can include respiratory depression, muscle and brain damage, and on rare occasions death (Gross, 1992). However, fatal overdoses are most common when benzodiazepines are combined with other substances such as alcohol or opioids (NIDA, 2018). In fact, over 30\% of opioid overdoses also involved benzodiazepines and $23 \%$ of fatal opioid overdoses involved benzodiazepines. Nevertheless, the rate of benzodiazepines co-prescribed with opioids increased from nine to seventeen percent between 2001 and 2013 (NIDA). Aside from the risk of overdose, benzodiazepine use is associated with various forms of risky behavior.

Benzodiazepine use has been associated with robbery and weapons-related crimes, increased likelihood of criminal behavior and memory loss in forensic psychiatric patients, increased antisocial behavior in violent criminals, and increased likelihood of poly-drug use (Daderman, 2005; Daderman \& Edman, 2001; Daderman et al., 2002). Benzodiazepine use has 
also been associated with increased risk of automobile accidents, unintentional drowning, and increased sexual disinhibition (Leung, 2011; Orriols et al., 2011; Pajunen et al., 2017; Simoes et al., 2009, Van der Sluiszen et al., 2017). Because benzodiazepines act primarily on GABA receptors, it is likely that these risk-increasing effects are mediated at least in part by the GABA system.

The GABA system has been implicated in maladaptive decision-making in human and non-human animals. Individuals with gambling disorders are more likely to have impaired GABA transmission and individuals with higher levels of cerebrospinal-fluid GABA are more impulsive than controls (Mick et al., 2017; Nordin \& Sjodin, 2007). In non-human animals, GABA dysregulation is associated with increased impulsivity and risk taking, and GABA agonists have been shown to produce impulsive responding in rats in a reaction-time task and increase choice for a larger reward that is associated with some probability of foot shock (Jupp et al., 2013; Mitchell et al., 2011; Murphy et al., 2012; Paine et al., 2011). There is also some evidence to suggest that individual differences in risk-taking may be related to differential genetic expression of GABA receptors in certain brain regions (Ucha et al., 2019). GABA agonists such as diazepam, alprazolam, and flunitrazepam have also been shown to affect risky choice in humans.

\section{Benzodiazepines and Risky Choice}

Several benzodiazepines have been studied for their effects on risky choice with humans. In one study, human subjects were given a range of doses of diazepam and tested on a battery of assessments, including a risky decision-making task. Subjects were instructed to choose between options with varying reward sizes and varying probabilities of delivery. Diazepam increased risky choice at $20 \mathrm{mg}$ which was the highest dose administered (Deakin et al., 2004). 
Alprazolam and flunitrazepam have also been shown to increase risky choice in risky decision-making tasks with humans (Lane et al., 2005; 2008). Lane and colleagues (2005) found that alprazolam administration dose-dependently increased risky choice in a computerized risktaking task. The computerized task required subjects to choose between a risky and a non-risky choice by making 25 responses on a computer-screen button. The non-risky choice produced $\$ 0.01$ and the risky choice produced either a gain or loss of $\$ 0.25-\$ 1.00$ with equal probability.

Lane and colleagues also administered flunitrazepam to human subjects in a separate (2008) study using the same computerized task and found that flunitrazepam also dosedependently increased risky choice. Notably, these studies employed procedures that deviate considerably from what may be considered "standard" pre-clinical models of risky choice, making comparisons of risky choice across species and experimental settings difficult. Indeed, little is known about how the performance of humans or non-human animals on probabilitydiscounting tasks is affected by benzodiazepines.

\section{Benzodiazepines and Tolerance}

Benzodiazepines are indicated for short-term (two to four weeks) relief of anxiety-related symptoms, but are may also be prescribed for much longer periods of time (Kaiser Permanente, 2019). Recreational users and individuals who abuse benzodiazepines may also use them for longer periods, with many individuals developing tolerance and dependence. However, little is known about how repeated, chronic use affects decision-making. Similarly, little is known about repeated exposure to benzodiazepines and the possible development of tolerance to their effects on risky choice.

In general, tolerance to the various effects of benzodiazepines develops at different rates and occurs due to changes in the quantity and function of GABA receptors rather than changes in 
drug metabolism (Ferreri et al., 2015; Hutchinson et al., 1996) Some studies have shown that in humans, tolerance to sedative effects develops in as little as 3-14 days (Johnson \& Streltzer, 2013; Potts \& Krishnan, 1992). In addition to tolerance, long-term use of benzodiazepines is associated with cognitive impairments, increased risk for automobile accidents, increased risk of hip fracture in elderly populations, sexual dysfunction, depression, disinhibition, and withdrawal symptoms (Cohen \& Rosenbaum, 1987; Ford \& Law, 2014; Johnson \& Streltzer; 2013). Despite clinical and experimental evidence that benzodiazepine use, especially prolonged use, is associated with numerous physiological and behavioral risks, little is known about how risky choice is affected by short- or long-term benzodiazepine use.

\section{Chlordiazepoxide}

Chlordiazepoxide (CDP) is a low- to medium-potency benzodiazepine with a relatively long half-life of 5 to 30 hours (Griffin et al., 2013). CDP is metabolized into desmethyldiazepam, which has a longer half-life of 40-120 hours, and oxazepam, which has a shorter half-life of 5-15 hours (Griffin et al., 2013). CDP's intermediate potency and long duration of action make it an ideal compound for experimental studies that test a range of doses in relatively long experimental sessions. CDP has been shown to produce numerous behavioral effects in rats, including increased social behavior, impaired acquisition of novel behavior, increased punished responding, increased aggression, and increased impulsivity (Bonuti \& Morato, 2018; Carinal et al., 2000; Evenden \& Ko, 2005; Manzo et al., 2015; McMillan \& Leander, 1978; Miczek \& Barry, 1977; Pitts et al., 2006).

\section{Statement of the Problem}

Risky choice is an important aspect of many forms of problematic behavior. Probabilitydiscounting procedures are well-established as an effective and efficient means of assessing risky 
choice. Benzodiazepines are a commonly prescribed class of drugs that are known to alter decision-making, yet little is known about their effects on probability discounting. To date, no experimental studies have analyzed how prolonged exposure to benzodiazepines affects probability discounting, or how tolerance to acute or chronic effects develop over time. Chlordiazepoxide is a benzodiazepine with a long duration of action that produces effects typical of the benzodiazepine drug class. The present study assessed how risky choice in a probabilitydiscounting procedure is affected by acute and chronic exposure to chlordiazepoxide, as well as how tolerance to any such effects develops.

\section{Method}

\section{Overview}

The experiment began with lever-press training in which food-pellets were initially delivered on a continuous schedule of reinforcement (each response on either lever produced food), and then on a probabilistic schedule of reinforcement (each response on either lever had a $50 \%$ chance of producing food). Next, a probability-discounting procedure was implemented in which a choice between a single food pellet delivered with $100 \%$ probability or three food pellets delivered with one of five probabilities $(100 \%, 50 \%, 25 \%, 12.5 \%, 6.25 \%)$ was available. The probability of the larger reinforcer being delivered decreased across blocks of trials within each session, and sessions were conducted until stable responding was observed (e.g., St. Onge et al., 2010).

Once stability was observed, rats were administered acute doses of CDP and tested using the same probability-discounting procedure. The acute-exposure phase of the study allowed for observation of how short-term exposure to CDP affected risky choice. Once all rats had received each acute dose at least twice, chronic CDP exposure began. Chronic exposure consisted of daily 
injections of an intermediate dose $(10.0 \mathrm{mg} / \mathrm{kg})$ of CDP for a minimum of 30 days, depending on stability of responding. Following chronic exposure, the procedure from the acute phase of the study was repeated with the caveat that the chronic dose was administered every day that acute doses were not. This replication of the acute phase of the study during chronic exposure allowed for observation of how chronic exposure to CDP affected risky choice over time, as well as how tolerance to risky-choice-altering effects of CDP developed.

\section{Subjects}

Eight experimentally naïve male Sprague-Dawley rats served as subjects during the acute phase of the study. Two rats died due to unrelated health issues during the chronic-exposure phase, leaving six rats for the remainder of the study. All rats were pair-housed in controlled environmental conditions (temperature, $24^{\circ} \mathrm{C}$; 12 -h reverse light/dark cycle), with continuous access to water in home cages. Sessions were conducted at approximately the same time each day, five days per week (Monday-Friday). Rats were fed approximately $13 \mathrm{~g}$ of food approximately $30 \mathrm{~min}$ following sessions, resulting in approximately $22 \mathrm{~h}$ of food restriction prior to each experimental session.

\section{Apparatus}

Sessions were conducted in eight standard operant-conditioning chambers for rats, each enclosed in a melamine sound-attenuating cubicle (Med Associates, VT). Each chamber contained a working area of $30.5 \mathrm{~cm}$ by $24.5 \mathrm{~cm}$ by $21.0 \mathrm{~cm}$, a grid floor, and a $45-\mathrm{mg}$ pellet dispenser with a pellet receptacle centered between two retractable response levers. Levers were $11.5 \mathrm{~cm}$ apart from each other and required at least $0.25 \mathrm{~N}$ of force for a response to be recorded. Levers were $4.8 \mathrm{~cm}$ wide, protruded $1.9 \mathrm{~cm}$ into the chamber, and were elevated $8 \mathrm{~cm}$ from the grid floor. Two 28-V stimulus lights, $2.5 \mathrm{~cm}$ in diameter, were approximately $7 \mathrm{~cm}$ above each 
lever. Each chamber had a $28-\mathrm{V}$ houselight on the wall opposite to the working wall, and a ventilation fan to circulate air and to mask extraneous noise. Data collection and programmed consequences were controlled by a personal computer equipped with Med-PC software (Med Associates, VT).

\section{Drugs}

Chlordiazepoxide hydrochloride (CDP, Sigma, St. Louis MO; 7-Chloro-2(methylamino)-5-phenyl-3H-1, 4-benzodiazepine 4-oxide hydrochloride) was dissolved in 0.9\% sodium-chloride solution on test days. Extra solution was stored in a refrigerator to prevent hydrolysis (Vinkers et al., 2010). CDP and its vehicle control (saline) were administered at a volume of $1 \mathrm{ml} / \mathrm{kg}$ intraperitoneally 15 minutes prior to the start of experimental sessions. Dosing and preparation procedures were adapted from previous research with CDP and operant behavior in rats (van Haaren \& Anderson, 1998; van Haaren, Katon, \& Anderson, 1997).

\section{Procedure}

\section{Lever-press Training}

At the beginning of each lever-press training session, both levers extended into the chamber and food pellets were delivered on a conjoint variable-time (VT) $60 \mathrm{~s}$ fixed-ratio (FR) 1 schedule of reinforcement. On this schedule, a food pellet was delivered an average of once every $60 \mathrm{~s}$ independent of responding, and immediately following any lever-press response. Lever pressing did not affect delivery of pellets from the VT component of the schedule and each of these sessions terminated following 60 food-pellet deliveries. If lever pressing had not been acquired after five sessions, it was shaped by reinforcement of successive approximations. After lever-press acquisition, an FR 1 schedule of reinforcement alternating between levers was implemented. Alternating FR 1 sessions consisted of one lever extending into the chamber with a 
cue light illuminated over it. A response on this lever resulted in the delivery of a single food pellet. The FR 1 contingency and cue light alternated between the left and right levers after every five responses. Alternating FR 1 sessions continued until lever pressing was consistent on both levers and each session terminated after the delivery of 40 food pellets.

\section{Probabilistic-Reinforcement Training}

After lever-press training was completed, probabilistic reinforcement training began (adapted from Ozga \& Anderson, 2018). These sessions consisted of 90 trials each, and trials were presented every $40 \mathrm{~s}$. Each trial consisted of a single, randomly determined lever being extended into the chamber for $10 \mathrm{~s}$, and a response on this lever produced a single food pellet with 50\% probability. Probabilistic-reinforcement training continued for a minimum of five sessions, and until fewer than 10 trials were omitted across three consecutive sessions.

\section{Probability-Discounting Procedure}

The probability-discounting procedures used in this study were based on those described in the work of Floresco et al. (2008). After probabilistic-reinforcement training was complete, the probability-discounting procedure was in effect for the remainder of the study. During the probability-discounting procedure, one lever was associated with a small/certain reinforcer and the other with a large/risky reinforcer. The position of the lever associated with each reinforcer was counterbalanced across rats and remained constant throughout the study. Each session began with a 10-minute blackout period followed by five blocks of trials, with 16 forced-choice and eight free-choice trials in each block. The probability of the large/risky reinforcer was $100 \%$ in the first block, and then decreased across blocks (100\%, 50\%, 25\%, 12.5\%, and 6.25\%).

In forced-choice trials, a single, randomly determined lever was inserted into the chamber and a cue light was illuminated above the lever. A response on the lever produced either a 
small/certain reinforcer (one food pellet, 100\% probability), or a large/risky reinforcer (three food pellets, varying probability). Pellet delivery was signaled by flashes of the houselight, with a single 0.1 -s flash occurring as each pellet was delivered. Levers retracted and a 20-s inter-trial interval (ITI) began as soon as the final food pellet was delivered at the end of each trial. To ensure that responding was exposed to the probability assigned to the lever that produced the large/risky reinforcer in each block, the probability of pellet delivery on each forced-choice trial was selected from a pre-determined sampling distribution, such that responses on that lever produced reinforcement on exactly one of 16 trials in the $6.25 \%$ block (approximately once every two blocks), one of eight trials for the 12.5\%-probability block, two of eight trials in the $25 \%$-probability block, and four of eight trials in the 50\%-probability block. Additionally, forced-choice trials were presented quasi-randomly such that a given lever would be presented on no more than two consecutive trials unless the other lever had already been presented eight times in each block of forced-choice trials.

In each block, 16 forced-choice trials were followed by eight free-choice trials. Freechoice trials consisted of both levers extending into the chamber with a cue light illuminating each. A response on either lever resulted in both levers being retracted, both cue lights being extinguished, and delivery of the reinforcer associated with the lever upon which the response occurred. A response on the lever associated with the small/certain reinforcer produced a single pellet and a 0.1-s flash of the houselight, and a response on the lever associated with the large/risky reinforcer produced four pellets and four flashes of the houselight, delivered with the programmed probability. Unlike forced-choice trials, probabilities for the large/risky reinforcer were independent for each trial, such that the probability of food-pellet delivery on a given trial was not affected by the outcome of preceding trials. After food-pellet delivery, a 20-s ITI began. 
If no response was made within $10 \mathrm{~s}$ of the beginning of a forced- or free-choice trial (an omission), the lever(s) would retract, cue lights would extinguish, and the 20-s ITI began. Sessions terminated after 120 total trials ( 80 forced-choice and 40 free-choice), or $60 \mathrm{~min}$ (including the 10-min blackout at the start of sessions), whichever occurred first.

\section{Baseline}

The baseline phase of the study consisted of a minimum of 20 sessions of probability discounting, with stability observed for all rats after no more than 21 days. Baseline responding was considered stable when the following criteria were met across five consecutive sessions: A two-way analysis of variance (ANOVA) showed a main effect of block and neither a main effect of session nor a session-by-block interaction, and visual inspection revealed no increasing or decreasing trends in the total percentage of responses for the large/risky reinforcer, and a minimum of $80 \%$ of responses (seven out of eight free-choice trials) for the large/risky reinforcer in the first free-choice block (when both reinforcers were delivered with $100 \%$ probability).

\section{Acute Chlordiazepoxide Administration}

Once baseline responding reached stability, the same procedures used to establish baseline probability-discounting functions were used to test effects of CDP and its vehicle

control (saline), with sessions conducted five days per week. CDP $(1,3,10,17$, and $30 \mathrm{mg} / \mathrm{kg}$ ) or saline was administered to all rats on Tuesdays and Fridays to determine acute effects on probability discounting and the relation between different doses and changes in risky choice (dose-response function). Control sessions occurred on Mondays and Thursdays, with Wednesday sessions being identical to control sessions.

Drug administration occurred only if the previous (control) day's larger-reinforcer choice in the first block was $80 \%$ or greater, and if the overall percent larger-reinforcer choices was 
within the range of the last five baseline sessions. For any test day on which drug-administration criteria were not met, those sessions were identical to control sessions and testing did not resume until drug-administration criteria were met. Vehicle was administered prior to drug administration in order to allow for habituation to the injection procedure and to determine any vehicle-induced effects on behavior.

Drug doses were administered in both ascending and descending sequences, with an additional administration of vehicle occurring between each sequence. Each dose of CDP was tested at least twice, with four rats starting with the highest dose and four rats starting with the lowest dose. Additional doses were administered if high variability in larger-reinforcer choice was observed on drug-administration days (see Table 1 for the number of administrations of each dose in each phase). The 17.0 and $30.0 \mathrm{mg} / \mathrm{kg}$ doses were administered fewer times because of increased omissions following initial administration of these doses (see Table 2 for the number of omissions at each dose in each phase).

\section{Chronic Chlordiazepoxide Exposure}

Following acute drug administration, CDP was administered daily. The $10.0 \mathrm{mg} / \mathrm{kg}$ dose was selected for chronic exposure because it was an intermediate dose that produced changes in larger-reinforcer choice without producing excessive omissions during the acute phase.

Probability-discounting sessions were conducted seven days per week, with chronic CDP doses administered 15 minutes prior to each session. Daily doses of $10.0 \mathrm{mg} / \mathrm{kg}$ CDP continued for a minimum of 30 sessions $(M=56.4)$ and until choice was stable. Stability was determined using the same criteria as the acute phase. Due to health issues that disrupted responding, responding for one rat required 97 days to reach stability.

\section{Chronic Dose-Response Determination}


Once responding was stable after at least thirty days of daily injections of $10.0 \mathrm{mg} / \mathrm{kg}$ CDP, the dose-response function was re-determined using the same procedures as in the acute phase of the study. Daily doses were administered at the same time of day as in the chronic dosing phase, and all doses were administered to each rat 15 minutes prior to sessions. If drugadministration criteria were not met on control days, the $10.0 \mathrm{mg} / \mathrm{kg}$ dose was still administered on test days (see "Acute chlordiazepoxide administration," above). The same range of doses were administered as in the acute phase to allow for comparisons of dose-response functions from before and after chronic exposure.

\section{Data Analysis}

In general, data analysis consisted of four categories of comparisons. First, data from acute test days were compared to determine how behavior changed following injections of either saline or the range of CDP doses (i.e., acute dose-response function). Next, data from the first and last

five days of the chronic-exposure phase were used to compare how behavioral measures changed as a function of chronic exposure to a single dose of CDP $(10.0 \mathrm{mg} / \mathrm{kg})$. Note that although this phase is referred to as the chronic-exposure phase, chronic exposure continued into the final phase of the study. In the final phase of the study, chronic injections of $10.0 \mathrm{mg} / \mathrm{kg}$ continued but the full range of CDP doses were substituted on test days. Data from these test days were used to compare changes in behavior following injections of either saline or the range of CDP doses in the context of chronic exposure (i.e., chronic dose-response function). Finally, data from the acute and chronic dose-response functions were compared to assess how CDP's effects on behavior changed as a function of chronic exposure.

\section{Dependent measures}


Dependent variables included percent larger-reinforcer choice, indifference points (IPs), area under the curve (AUC), win-stay ratios (WSRs), and lose-shift ratios (LSRs). Percent largerreinforcer choice was calculated block-by-block by dividing the number of free-choice trials in which the larger reinforcer was selected by the total number of free-choice trials per block. A session-by-session measure of percent larger-reinforcer choice was also calculated by dividing the number of responses for the larger reinforcer during free-choice trials by the total number of free-choice trials in a session. IPs were calculated by fitting a regression line to obtained data and interpolating the probability at which choice for both reinforcers was equivalent.

To calculate AUC, probability of delivery was converted to "odds against delivery" by determining the average number of unreinforced responses required before a reinforcer would be delivered. For example, a $25 \%$ probability of delivery was converted to an odds-against value of three because three unreinforced responses, on average, would occur before a reinforcer would be delivered. Percent larger-reinforcer choice was plotted as a function of odds-against values and vertical lines were drawn from each data point to the $\mathrm{x}$-axis of the graph. Doing so created four trapezoids under the discounting curve that were summed to determine the total area of the graph beneath the curve. AUC was expressed as the proportion of the entire graph area consumed by the trapezoids.

WSRs and LSRs were calculated by identifying whether a response was made for the small/certain or large/risky reinforcer during free-choice trials, and whether the prior response resulted in food-pellet delivery (a "win" or "loss"). Win-stay ratios consisted of the number of responses for the large/risky reinforcer during free-choice trials that followed a "win" divided by the total number of responses that resulted in a "win." Essentially, WSRs were the proportion of trials that followed a "win" on which responding stayed allocated toward the large/risky 
reinforcer. Lose-shift ratios consisted of the number of responses for the small/certain reinforcer that followed a loss divided by the total number of responses that resulted in a "loss." Essentially, LSRs were the proportion of trials that followed a "loss" on which responding shifted away from the large/risky reinforcer. Omission frequency was also recorded and analyzed as a secondary dependent variable.

\section{Acute Chlordiazepoxide Administration}

Dose-response functions for percent larger-reinforcer choice, IP and AUC were determined and visually analyzed. Overall percent larger-reinforcer choice and AUC were expected to increase dose-dependently. Changes in these variables was assessed for statistical significance with a series of repeated-measures analyses of variance (ANOVAs) and paired-samples t-tests.

\section{Chronic Chlordiazepoxide Exposure}

To assess changes in percent larger-reinforcer choice, IPs, AUC, WSRs, and LSRs as a function of chronic drug exposure, data from the first and last five days of the chronic phase were graphed for visual analysis. Statistical significance was assessed using repeated-measures ANOVAS and paired-samples t-tests. Two rats died during the chronic-exposure phase of the study. Therefore, all analyses of chronic drug effects and comparisons of acute and chronic effects utilized a total of six rats.

\section{Chronic Dose-Response Determination}

The same measures used in the acute phase were assessed after chronic CDP exposure using visual analysis, repeated-measures ANOVAs, and paired-samples t-tests. Acute and chronic effects were also compared to one another using visual analysis, repeated-measures ANOVAs, and paired-samples t-tests. Due to a global pandemic, laboratory facilities were closed prior to the completion of the final dose-response determination. Complete data sets were collected for 
two rats, and partial data sets were collected for four rats. Missing data were excluded on an analysis-by-analysis basis.

\section{Results}

\section{Baseline}

Figure 1 displays the mean percent larger-reinforcer choice for all rats $(\mathrm{N}=8)$ during each trial block under saline, $1.0,3.0$, and $10.0 \mathrm{mg} / \mathrm{kg}$ CDP. Note that data for the acute 17.0 and 30.0 $\mathrm{mg} / \mathrm{kg}$ doses were omitted from all analyses because those doses disrupted magnitude discrimination and increased trial omissions (see Table 1). Under saline, percent larger-reinforcer choice decreased as a function of probability of delivery, indicating that responding was sensitive to the programmed contingencies $[F(2.04)=123.40, p<.01]$.

\section{Acute Percent Larger-Reinforcer Choice}

Figures 1 and 2 show percent larger-reinforcer choice as a function of probability of delivery for group and individual means, respectively. CDP increased percent larger-reinforcer choice relative to saline $[F(3)=4.57, p=.01]$, particularly in the final three blocks, which indicates increased risky choice. This effect was most pronounced at the 3.0 and $10.0 \mathrm{mg} / \mathrm{kg}$ doses (see Figure 3). Pairwise comparisons indicated that $3.0 \mathrm{mg} / \mathrm{kg} \mathrm{CDP}(M=60.42, S E=4.78$, $p<.01)$ and $10.0 \mathrm{mg} / \mathrm{kg} \mathrm{CDP}(M=65.83, S E=3.92, p=.02)$ significantly increased percent larger-reinforcer choice relative to saline, although $1.0 \mathrm{mg} / \mathrm{kg}$ CDP also increased percent largerreinforcer choice in the third block.

A significant dose $\mathrm{x}$ block interaction was observed $[F(3.49)=2.58, p=.02]$, indicating that CDP increased percent larger-reinforcer choice in some blocks more than others. To further elucidate CDP's effects on percent larger-reinforcer choice at the block-by-block level, a series of paired-samples t-tests were conducted. Statistically significant increases in percent larger- 
reinforcer choice occurred primarily in the third block. At the $1.0 \mathrm{mg} / \mathrm{kg}$ dose, percent largerreinforcer choice was significantly higher in the third block, $t(7)=3.38, p=.01$, relative to saline. At the $3.0 \mathrm{mg} / \mathrm{kg}$ dose, percent larger-reinforcer choice was significantly higher in the third block as well, $t(7)=4.13, p<.01$. At the $10.0 \mathrm{mg} / \mathrm{kg}$ dose, larger-reinforcer choice was also significantly higher in the third block, $t(7)=3.93, p<.01$. An increase in larger-reinforcer choice was also observed in the fourth block under $10.0 \mathrm{mg} / \mathrm{kg}$ CDP but was not statistically significant. See Table 2 for means and SEM for percent larger-reinforcer choice during each block at each dose.

\section{AUC, IPs, WSRs, and LSRs}

Figure 4 displays mean AUC under saline and each dose of CDP. CDP significantly increased AUC relative to saline $[F(3)=3.61, p=.03]$, indicating increased risky choice. This effect was most pronounced at the 3.0 and $10.0 \mathrm{mg} / \mathrm{kg}$ doses. A series of paired-samples t-tests were conducted to examine changes in AUC at each dose of CDP relative to saline. AUC was significantly higher under $3.0 \mathrm{mg} / \mathrm{kg} \mathrm{CDP}[t(7)=3.52, p=.01]$ and $10.0 \mathrm{mg} / \mathrm{kg} \mathrm{CDP}[t(7)=$ $2.59, p=.04]$. There was no statistically significant effect of dose on IPs, WSRs, or LSRs at any dose of CDP. See Table 3 for means and SEM for AUC, IPs, WSRs, and LSRs at each dose of CDP.

\section{Omissions}

Omissions occurred more frequently under CDP than saline during acute drug exposure (see Table 1). This effect was most pronounced at the 17.0 and $30.0 \mathrm{mg} / \mathrm{kg}$ doses. A main effect of dose was detected $[F(5)=35.30, p<.001]$, indicating that omissions occurred more often following CDP administration. Post-hoc tests revealed that omissions occurred significantly 
more often at the $17.0 \mathrm{mg} / \mathrm{kg}(M=25.13, S E=15.48, p=.04)$ and $30.0(M=42.00, S E=15.47$, $p<.01) \mathrm{mg} / \mathrm{kg}$ doses relative to saline $(M=0.34, S E=0.55)$.

\section{Chronic CDP Exposure}

Figure 5 displays mean percent larger-reinforcer choice during each block for the first and last five days of the chronic-exposure phase, as well as under saline during baseline. Note that all analyses after the initial acute-exposure phase were conducted with a total of six rats $(\mathrm{N}=6)$. Percent larger-reinforcer choice increased relative to saline during initial chronic exposure to $10.0 \mathrm{mg} / \mathrm{kg} \operatorname{CDP}[F(2)=4.41, p=.04]$ but subsided to near-baseline levels by the final five days of chronic exposure. IPs, AUC, WSRs and LSRs were not significantly different from baseline at either the beginning or the end of the chronic-exposure phase (see Figures 6-8). See Table 4 for means and SEM for all dependent measures during the first and last five days of the chronicexposure phase, as well as under saline.

\section{Chronic Percent-Larger Reinforcer Choice}

Figure 9 shows percent larger-reinforcer choice as a function of probability of delivery at each dose of CDP during chronic drug exposure. Note that the 17.0 and $30.0 \mathrm{mg} / \mathrm{kg}$ doses are included in the figure, as once tolerance to CDP developed these doses no longer suppressed responding after rats had been exposed to chronic CDP. CDP increased percent larger-reinforcer choice relative to saline, $F(5)=11.37, p<.01$, indicating an increase in risky choice. This effect was most pronounced at the higher doses $(10.0,17.0$, and $30.0 \mathrm{mg} / \mathrm{kg})$. Pairwise comparisons revealed a statistically significant effect of CDP relative to saline $(M=41.58, S E=3.77)$ at the $10.0(M=59.75, S E=2.54, p<.01), 17.0(M=57.00, S E=3.46, p=.03)$, and $30.0(M=62.75$, $S E=4.50, p<.01) \mathrm{mg} / \mathrm{kg}$ doses. This effect was most pronounced in the third block (see Figures 9 and 10). 
A significant dose $\mathrm{x}$ block interaction was observed, $F(20)=4.25, p<.01$, indicating that CDP increased percent larger-reinforcer choice in some blocks more than others. To further elucidate CDP's effects on percent larger-reinforcer choice at the block-by-block level, a series of paired-samples t-tests were conducted. At this level of analysis, percent larger-reinforcer choice was significantly higher only at the $30.0 \mathrm{mg} / \mathrm{kg}$, and only in the third block. Visual analysis of Figures 9 and 10 suggests that 10.0 and $17.0 \mathrm{mg} / \mathrm{kg}$ also increased percent largerreinforcer choice in the third block.

Figure 10 shows mean percent larger-reinforcer choice as a function of probability of delivery for individual rats during chronic drug exposure. CDP increased larger-reinforcer choice for most rats, except for Rat 4. For Rat 4, larger-reinforcer choice was highest under saline and decreased when CDP was administered. Larger-reinforcer choice under saline for Rat 4 was also relatively higher than for other rats. This baseline-dependent pattern of responding was only evident during chronic drug exposure, and only for the one rat.

\section{Chronic AUC, IPs, WSRs, and LSRs}

Figures 11 and 12 show AUC and IPs, respectively, as a function of drug dose. AUC was higher under CDP relative to saline, indicating increased risky choice, but this increase was not statistically significant. IPs were also higher at each dose of CDP relative to saline, indicating increased risky choice. This effect was statistically significant $[F(5)=5.32, p<.01]$, and pairwise comparisons revealed a statistically significant effect at the $30.0 \mathrm{mg} / \mathrm{kg}$ dose $[t(4)=$ $3.52, p=.04]$. There was no significant effect of CDP on WSRs or LSRs.

\section{Chronic Omissions}

During chronic exposure to $10.0 \mathrm{mg} / \mathrm{kg} \mathrm{CDP}$, higher doses of CDP $(17.0$ and $30.0 \mathrm{mg} / \mathrm{kg})$ did not significantly increase the number of omissions (see Table 1). In the context of chronic 
exposure, omissions were significantly more frequent under saline $(M=2.43, S E=0.54, p=0.1)$ than $10.0 \mathrm{~m} / \mathrm{kg} \operatorname{CDP}(M=0.15, S E=0.15)$.

\section{Acute vs Chronic Comparisons}

Figure 13 shows percent larger-reinforcer choice as a function of probability of delivery for saline during acute and chronic drug exposure. Percent larger-reinforcer choice under saline did not change significantly as a function of chronic CDP exposure, indicating that risky choice returned to baseline levels when chronic doses were replaced with saline. Figure 14 shows percent larger-reinforcer choice as a function of drug dose during acute and chronic drug exposure. Note that higher doses of CDP were required to reach the same levels of largerreinforcer choice seen during the acute phase (a rightward shift from the acute curve to the chronic curve), but this effect was not statistically significant. Across doses, omissions were less frequent during chronic drug exposure, $F(1)=23.85, p<.01$ (see Table 1). CDPs effects on AUC, IPs, WSRs and LSRs did not change significantly as a function of chronic exposure.

\section{Discussion}

The present study was designed to assess how CDP might affect risky choice in a probability-discounting procedure. The procedure used in the present study was an effective tool to assess changes in risky choice following acute and chronic administration of CDP. Under baseline conditions, responding was sensitive to the programmed contingencies and largerreinforcer choice decreased as a function of probability of delivery. During acute drug exposure, CDP dose-dependently increased larger-reinforcer choice, i.e., risky choice.

After chronic drug exposure, larger-reinforcer choice returned to baseline levels and higher doses of CDP were required to increase larger-reinforcer choice, indicating tolerance to CDP's effects. The highest doses of CDP (17.0 and $30.0 \mathrm{mg} / \mathrm{kg}$ ) produced excessive omissions 
in the acute phase but not after chronic drug exposure, providing further evidence for the development of tolerance. The development of tolerance to CDP's effects stands in accordance with prior research on tolerance to certain effects of benzodiazepines (e.g., Bourin, 2019; Gravielle, 2016; Johnson \& Streltzer, 2013; McMillan \& Leander, 1978; Potts \& Krishnan, 1992; Rosenberg \& Chiu, 1985; Sannerud et al., 1993). However, the results of the present study are the first to demonstrate tolerance to CDP's effects on risky choice.

\section{Clinical Implications for Tolerance}

Development of tolerance to CDP-induced increases in risky choice may be advantageous from a clinical perspective. Acute exposure to CDP has been previously shown to increase risky choice in several experimental paradigms and is associated with increases in a variety of maladaptive behaviors (Daderman, 2005; Daderman \& Edman, 2001; Daderman et al., 2002; Deakin et al., 2004; Lane et al., 2005; 2008; Leung, 2011; Orriols et al., 2011; Pajunen et al., 2017; Simoes et al., 2009, Van der Sluiszen et al., 2017). Results of the present study suggest that increases in risky choice may not persist indefinitely, and that individuals prescribed CDP for long periods of time may not continue to engage in increased risky choice. This could be particularly beneficial given that there is little evidence that tolerance to the anxiolytic effects of CDP develops in humans (for reviews, see Hood et al., 2012; Vinkers \& Olivier, 2012).

Although the development of tolerance observed in the present study may be beneficial from a clinical perspective, increases in risky choice prior to the development of tolerance would not be. CDP increased risky choice during the acute-exposure phase and at higher doses after chronic exposure. These findings add to the existing literature that CDP increases risky choice, although the present findings are the first to demonstrate an increase in risky choice in a 
probability-discounting procedure and to show the development of tolerance to such effects

(Deakin et al., 2004; Lane et al., 2005; 2008).

\section{GABA, Risky Choice and Schizophrenia}

Because CDP is a GABA agonist, the present data support the notion that the GABA system may be an important factor in risky choice. These results are in line with prior research that has demonstrated that the GABA system is involved in risky choice (Bidwell et al., 2013; Murphy et al., 2012; Paine, et al., 2011; Schindler, et al., 2014; Ucha et al., 2019). These results also demonstrate that effects of CDP on risky choice are similar to those of ethanol, which also acts on the GABA system (Wallin-Miller et al., 2017).

The GABA system may interact with risky choice in several ways. Disruption of GABA receptors (reduced GABA transmission) in the prefrontal cortex of rats has been shown to increase reward sensitivity but reduce risky choice (Piantadosi et al., 2016). While reward sensitivity (as measured by WSRs) was not altered in the present study, benzodiazepines have been shown to alter GABA activity in the prefrontal cortex and associated behavioral outcomes (e.g., Dominguez et al., 2018; Lissek et al., 2017). GABA disruption in the prefrontal cortex has also been associated with increased omissions in choice procedures and spatial discrimination errors in radial-maze tasks (Auger \& Floresco, 2014; Paine et al., 2011; 2015, Piantadosi \& Floresco, 2014). Such disruptions may explain why an increased number of omissions were observed under saline during the chronic-exposure phase of the present study. That is, chronic exposure to CDP likely resulted in decreased responsiveness of the GABA system, at which point administration of saline instead of the chronic dose of CDP could have caused a deficit in GABA signaling (e.g., Allison \& Pratt, 2003; Bateson 2002). 
Disrupted GABA signaling may be related to some of the symptoms seen in psychiatric disorders such as schizophrenia. Deficits in attention, working memory, impulse control, discrimination of conditioned fear signals, cue salience, and decision-making are features of impaired GABA functioning that share some similarities with symptoms of schizophrenia (e.g., Auger \& Floresco, 2014; Kim et al., 2009; Lissek et al., 2017; Paine et al., 2011; 2015; Piandosi \& Floresco, 2014; Piandosi et al., 2016; Shurman et al., 2005). The results of the present study provide further evidence that the GABA system may be an attractive target for research on pharmacological treatments for symptoms of disorders such as schizophrenia.

\section{Delay and Probability Discounting}

The current study adds to the body of evidence that pharmacological manipulations can produce differential results in delay- and probability-discounting procedures. Prior research on benzodiazepines and delay discounting has been mixed. In one procedure, flunitrazepam decreased delay discounting (decreased impulsive choice) in pigeons at all delay values (Eppolito et al., 2011). In a study with Lewis and Fischer 344 with rats, low doses of diazepam increased delay discounting while higher doses decreased delay discounting for Fischer 344 rats

but had no effect on Lewis rats (Huskinson \& Anderson, 2012). On the other hand, diazepam has not produced changes in measures of delay discounting in rhesus monkeys or humans (Maguire et al., 2012; Reynolds et al., 2004). In contrast, CDP consistently and dose-dependently increased larger-reinforcer choice in the present study.

\section{Measurement}

The present study employed several measures, some of which were selected because of their utility in delay-discounting procedures. Percent larger-reinforcer choice, a direct measure of responding, is based only on the assumption that changes in larger-reinforcer choice indicate 
changes in risky (or impulsive) choice. This assumption is accepted at all delay values in delay discounting because it is always advantageous to choose the larger reinforcer, and choosing the smaller reinforcer is always considered impulsive. In probability discounting, however, choosing the larger reinforcer is advantageous only when the probability of delivery is relatively high. Thus, increases in larger-reinforcer choice are only said to reflect increased risky choice when the odds of delivery are relatively low. Therefore, measures based on whole-session responding (high- and low-probability trials) may not reflect risky choice as accurately as block-by-block measures.

\section{Whole-Session Measures}

AUC and IPs appeared to be less sensitive than percent larger-reinforcer choice as measures of risky choice. Although AUC and IPs are derived from larger-reinforcer choice, they are calculated using whole-session responding rather than block-by-block responding. Changes in larger-reinforcer choice that occurred at lower probabilities (i.e., the third, fourth, and fifth blocks) may not have been large enough to significantly increase AUC and IPs in most cases. While these measures are commonly used in delay-discounting studies, they may not be appropriate for analyzing probability-discounting data.

AUC and IPs should be interpreted with caution for several reasons. In the present study, changes in responding in the first two blocks do not indicate changes in risky choice yet are factored into the calculation of AUC and IPs. Additionally, larger-reinforcer choice in the first two blocks was often at or near 100\%. Thus, increases in larger-reinforcer choice in later blocks, while significant on their own, may not have been large enough to produce a significant change in overall AUC or IPs. 
Although AUC and IPs may not adequately characterize risky choice in probabilitydiscounting procedures, these measures do have one advantage over percent larger-reinforcer choice. AUC and IPs take into account the relative differences in probability of delivery for each block. For example, the portions of the graph that are summed to calculate AUC become larger as the odds against delivery become greater (as probability of delivery decreases). This means that an increase in larger-reinforcer choice in the final block would increase the overall AUC more than an identical increase in larger-reinforcer choice in the first block. Similarly, the regression line that is fitted to raw data and used to interpolate IPs weights changes in largerreinforce choice more heavily as the odds against delivery increase.

\section{Block-by-Block Measures}

Block-by-block measures of risky choice (i.e., larger-reinforcer choice) were most sensitive to CDP's effects, but did not take into account changes in the risk associated with larger-reinforcer choice across blocks. Changes in larger-reinforcer choice were most evident in the third trial block, with clear increases also observed in the fourth, and to a lesser extent, fifth blocks. In the third block, the probability of delivery was $25 \%$. Over repeated trials, this response option would yield an average of 0.75 pellets/response (compared to 1.0 pellet/response for the small/certain option across all blocks). The difference in average yield between the two response options was smallest in the third block with a difference of 0.25 pellets/response. As the difference in average yield between the response options increased across blocks, CDP's effect on larger-reinforcer choice became smaller and smaller. This suggests that as the discriminability of the two contingencies in each block increased, larger-reinforcer choice was less sensitive to CDP's effects. 
In the fifth block, with a very low probability of reinforcer delivery and an average larger-reinforcer yield of only 0.19 pellets/response, responding for the large/risky reinforcer was rarely reinforced. Considering the low rates of responding and the equally low probability of reinforcement in this block, increases in percent larger-reinforcer choice may carry more theoretical weight (i.e., be considered riskier) than in other blocks with higher rates of reinforcement (Yates, 2019). That is, it is possible that the disparity in average larger-reinforcer yield became more and more discriminable as the probability of reinforcer delivery decreased across blocks. Therefore, increases in larger-reinforcer choice during the final block may reflect a stronger effect than a similar increase in prior blocks.

\section{Individual Differences}

Behavior analysis is rooted in single-subject experimental designs, yet discounting research often employs group designs (Sidman, 1988). In the present study, larger-reinforcer choice for Rat 1 was increased to nearly $100 \%$ by the $10.0 \mathrm{mg} / \mathrm{kg}$ acute dose across all blocks. This extreme increase in later blocks was not evident in any other doses or rats. This pattern continued during the chronic phase to a lesser extent, with larger-reinforcer choice for Rat 1 consistently higher than for any other rats in the third block. It is unclear what may have caused this individual difference in responding.

A baseline-dependent effect appears to have occurred for one rat during chronic exposure. Larger-reinforcer choice for Rat 4 was consistently higher than for all other rats under saline, and contrary to its effect on responding for all other rats, larger-reinforcer choice was decreased following CDP administration. It is worth noting that during the chronic phase of this experiment, rats had been receiving daily doses of $10.0 \mathrm{mg} / \mathrm{kg}$ CDP for at least 50 days. Therefore, increases in larger-reinforcer choice relative to $10.0 \mathrm{mg} / \mathrm{kg}$ are a more relevant 
indicator of CDP's effects. Nonetheless, for all other rats, larger-reinforcer choice was decreased by saline administration and decreased by CDP administration in the chronic phase.

\section{Limitations and Future Directions}

There were several limitations to the present study. During the acute-exposure phase, each rat received each dose of CDP at least twice. However, due to unforeseen emergent circumstances, data collection was concluded before the same number of data points could be acquired for each dose after chronic drug exposure. Furthermore, two rats died at the beginning of the chronic-exposure phase, leaving the total number of rats available for cross-phase comparisons at six. Undoubtedly, the reduced number of data points and the overall reduced sample size reduced the statistical power of all analyses conducted after the acute phase. This lack of power may have contributed to the apparent lack of significant effects of CDP on some measures, such as AUC and IPs. Despite these limitations, the present study provides evidence that CDP increases risky choice, and that tolerance to this effect develops over time.

Another limitation to the present study was that all the rats used as subjects were male. Prior research has demonstrated sex-specific differences in baseline decision making, as well as sexdependent drug effects. Ethanol, a GABA agonist, has been shown to increase risky choice in male rats, but not females (Wallin-Miller et al., 2017). Interestingly, a separate study demonstrated that testosterone may alter risky choice in males by increasing loss aversion and decreasing reward sensitivity (Wallin-Miller et al., 2015). Taken together, these findings indicate that there may be significant sex-specific differences in risky choice both before and after exposure to GABA agonists. Such differences limit the generality of the present study's findings.

Future research should consider how different manipulations of probability and reinforcer magnitude affect risky choice. The present study used one- and three-pellet reinforcer 
magnitudes for the small/certain and large/risky response options, respectively. Prior studies have used a variety of reinforcer magnitudes, with varying discrepancies between the small/certain and large/risky options (e.g., Bidwell et al., 2013; St. Onge et al., 2010; Yates, 2019). It is unknown how changes in reinforcer discrepancy affect risky choice. Similarly, the present study used a range of probabilities that differed from previous research. Prior studies have employed several various ranges of probabilities (e.g., 100/66/33/16.5\%, 100/50/25/0\%), often in combination with larger-reinforcer magnitudes that result in only the block with the lowest probability providing a risky choice (i.e., a choice involving a large/risky response option with a lower average yield than the small/certain option). The present study included three blocks with probabilities in which, given the three-pellet reinforcer magnitude, larger-reinforcer choice was considered risky. Further research should elucidate how different combinations of reinforcer magnitude and probability of delivery affect risky choice.

In the present study, larger-reinforcer choice was optimal (not risky) in the first two blocks. While the first (100\%) block served the purpose of ensuring that responding discriminated between the larger and smaller reinforcers when probability of delivery was equal, the second $(50 \%)$ block served no such purpose. Future research should assess the effects and utility of including multiple probabilities at which choice for the larger reinforcer is optimal. It is possible that including multiple blocks without risky options could affect responding in later blocks with riskier response options. In either case, including more than a single block with a high probability of reinforcer delivery may not be necessary.

Because the relative riskiness of larger-reinforcer choice changes with different probabilities of delivery, a measure that accounts for relative risk but excludes responding at high probabilities of delivery could prove useful. Probability-discounting procedures represent a 
relatively new behavioral paradigm that is distinct from delay discounting. While some of the structural features of delay-discounting procedures have been useful in developing probabilitydiscounting procedures, measures and methods of data analysis unique to probability discounting are needed (e.g., Green \& Myerson, 2019; Yates, 2019). Still, modern probability-discounting research has yet to employ novel measures of probability discounting (e.g., Islas-Preciado et al., 2020; Ozga \& Anderson, 2019; Yates et al., 2019).

A novel measure for probability discounting would need to address several issues. First, an improved measure of probability discounting should weight greater amounts of risk (i.e., lower probabilities of delivery) more heavily than lesser amounts of risk. Secondly, such a measure should exclude any trial blocks in which the expected value of the larger reinforcer is equal to or greater than that of the smaller reinforcer. For example, an economist might define risk as the difference between optimal and obtained outcomes in a choice scenario (Keeney \& Raiffa, 1993).

In the present study, risk could be conceptualized as the difference in average yields between the smaller and larger reinforcer at a given probability. A response for the smaller reinforcer in the third block has an average yield of 1.0 pellets/response. A response for the larger reinforcer in the third block has an average yield of 0.75 pellets/response, so the risk associated with larger-reinforcer choice in the third block is $(1.0-0.75) 0.25$. Probability of delivery is four times smaller in the fifth block, so the risk is accordingly higher as well at 0.8125. These measures of risk could then be used to weight a measure such as larger-reinforcer choice in statistical analyses. While this measure would need to be adjusted to account for actual obtained number of reinforcers and suboptimal responding in baseline, it meets the requirements described above and lends itself well to statistical analysis. 
Although the present study adds to the body of evidence that implicates the GABA system in risky choice, changes in GABA were not directly measured. To further clarify the relation between benzodiazepines, GABA, and risky choice, GABA receptors could be further manipulated. For example, a drug that prevents CDP from increasing GABA activity (a GABA antagonist) could be administered. Bicuculline is one such antagonist (for a review of GABA antagonists, see Johnston, 2013). Comparisons of risky choice after exposure to CDP in combination with bicuculline and exposure to CDP alone could help elucidate effects of CDP and the role of GABA in risky choice. This line of inquiry could be further pursued by investigating effects of specific subunits of GABA receptors. Although the $\mathrm{GABA}_{\mathrm{A}}$ subtype is thought to be the primary contributor to changes in anxiety and risky choice, GABAA receptors can further be divided into six subunits.

Some subunits of the $\mathrm{GABA}_{\mathrm{A}}$ receptor are differentially associated with specific benzodiazepine effects (for a review, see Sigel \& Steinmann, 2012). The $\alpha 1$ subunit is involved in sedation and amnesia, while $\alpha 2$ and $\alpha 3$ are involved in anxiolysis. The $\alpha 5$ subunit is associated with benzodiazepine-related impairments in learning and memory. It is therefore possible that one or more subunits is differentially involved in risky choice. Pharmacological manipulation of specific subunits could help to pinpoint with greater specificity the mechanism by which CDP and GABA affect risky choice (e.g., Fischer, 2011; Jansen et al., 2008; Schwienteck et al., 2017). Such knowledge could also aid in determining the mechanisms by which differential tolerance to the therapeutic and iatrogenic effects of CDP develops.

Future research on probability-discounting and CDP should also investigate the possibility of baseline-dependent effects. A baseline-dependent effect was observed for a single rat during 
one phase of the present study. Because baseline risky choice was otherwise relatively homogeneous, it is unclear if this effect would have been more pronounced in a sample with varying levels of baseline risky choice. This could be accomplished by assigning animals to experimental conditions based on their natural baseline behavior or by artificially inducing different baseline behavior through procedural manipulations. A third possibility would be to compare CDP's effects on different strains of rats with different baseline levels of risky choice (e.g., Huskinson et al., 2012, Ozga \& Anderson, 2018).

\section{Summary and Conclusions}

As a result of incomplete data collection and reduced statistical power in the present study, some of the results should be interpreted with caution. However, there are at least two conclusions that can be drawn with relative confidence regarding effects of CDP on risky choice: acute administration of CDP dose-dependently increased larger-reinforcer choice and chronic exposure to CDP resulted in tolerance to those effects. Furthermore, no changes in WSRs or LSRs were observed at any dose of CDP. Therefore, it is unlikely that increases in largerreinforcer choice were driven by changes in reinforcer sensitivity or loss sensitivity.

The results of the present study indicate that further research is necessary to better understand how CDP and other benzodiazepines affect complex behavior. While CDP did increase larger-reinforcer choice, choosing between smaller/certain outcomes and large/risky outcomes is a necessary but not sufficient feature of risky choice in humans (e.g., Green \& Myerson, 2019). Furthermore, whole-session measures of choice such as AUC and IPs should be used with caution as measures risky choice. Although increased risky choice is not a listed sideeffect of benzodiazepines, the present study adds to the body of research indicating that benzodiazepines can increase risky choice (e.g., Ahwazi \& Abdijadid, 2019). The results of the 
present study are novel in that they demonstrate that CDP increases risky choice in a probabilitydiscounting procedure, and importantly that tolerance to this effect develops over time. 


\section{References}

Ahwazi, H. H. \& Abdijadid, S. (2019). Chlordiazepoxide. In StatPearls. Treasure Island, FL: StatPearls.

Allison, C. \& Pratt, J. A. (2003). Neuroadaptive processes in GABAergic and glutamatergic systems in benzodiazepine dependence. Pharmacology and Therapeutics, 171-195. https://dx.doi.org/10.1017/S0163-7258(03)00029-9

Anderson, I. M., Richell, R. A., \& Bradshaw, C. M. (2003). The effect of acute tryptophan depletion on probabilistic choice. Journal of Psychopharmacology, 17(1), 3-7. https://dx.doi.org/10.1177/0269881103017001687

Auger, M. L., \& Floresco, S. B. (2014). Prefrontal cortical GABA modulation of spatial reference and working memory. International Journal of Neuropsychopharmacology, 1-11. https://dx.doi.org/10.1093/ijnp/pyu013

Barbelivien, A., Billy, E., Lazarus, C., Kelche, C., \& Majchrzak, M. (2008). Rats with different profiles of impulsive choice behavior exhibit differences in responses to caffeine and damphetamine and in medial prefrontal cortex 5-HT utilization. Behavioural Brain Research, 187(2), 273-283. https://dx.doi.org/10.1016/1.bbr.2007.09.020

Bari, A., Theobald, D. E., Capriolo, D., Mar, A. C., Aidoo-Micah, A., Dalley, J. W., \& Robbins, T. W. (2010). Serotonin modulates sensitivity to reward and negative feedback in a probabilistic reversal learning task in rats. Neuropsychopharmacology, 35, 1290-1301. https://dx.doi.org/10.1038/npp.2009.233

Bateson, A. N. (2002). Basic pharmacological mechanisms involved in benzodiazepine tolerance and withdrawal. Current Pharmaceutical Design, 8(1), 5-21. https://dx.doi.org/10.2174/1381612023396681 
Berry, M. S., Johnson, P. S., Collado, A., Loya, J. M., Yi, R., \& Johnson, M. W. (2019). Sexual probability discounting: A mechanism for sexually transmitted infection among undergraduate students. Archives of Sexual Behavior, 48, 495-505. https://dx.doi.org/10.1007/s10508-018-1155-1

Bidwell, L. C., MacKillop, J., Murphy, J. G., Grenga, A., Swift, R. M., \& McGeary, J. E. (2013). Biphasic effect of alcohol on delay and probability discounting. Experimental Clinical Psychopharmacology, 21(3), 214-221. http://dx.doi.org/10.1037/a0032284

Blaes, S. L., Orsini, C., Mitchell, M. R., Spurrell, M. S., Betzhold, S. M., Vera, K., Bizon, J. L., \&Setlow, B. (2018). Monoaminergic modulation of decision-making under punishment in a rat model. Behavioural Pharmacology, 29(8), 745-761.

https://dx.doi.org/10.1097/FBP.0000000000448

Bonuti, R., \& Morato, S. (2018). Proximity as a predictor of social behavior in rats. Journal of Neuroscience Methods, 293, 37-44. https://dx.doi.org/10.1016/j.neumeth.2017.08.027

Bourin, M. (2019). The test retest model of anxiety: An appraisal of findings to explain benzodiazepine tolerance. Pharmacology Biochemistry and Behavior, 178, 39-41. https://doi.org/10.1016/j.pbb.2017.12.009

Cardinal, R. N., Robbins, T. W., \& Everitt, B. J. (2000). The effects of d-amphetamine, chlordiazepoxide, alpha-flupenthixol, and behavioural manipulations on choice of signaled and unsignalled delayed reinforcement in rats. Psychopharmacology, 152(4), 362-375.

Chuang, C. I., Sussman, S., Stone, M. D., Pang, R. D., Chou, C., Leventhal, A. M., \& Kirkpatrick, M. G. (2017). Impulsivity and history of behavioral addictions are associated with drug use in adolescents. Addictive Behaviors, 74, 41-47. http://dx.doi.org/10.1016/j.addbeh.2017.05.021 
Cohen, L. S., \& Rosenbaum, J. F., (1987). Clonazepam: new uses and potential problems. Journal of Clinical Psychiatry, 48, 50-56.

Cui, R., Wang, L., Liu, L., Ruan, H., \& Li, X. (2018). Effects of noradrenergic and serotonergic systems on risk-based decision-making and center arena activity in open field in rats. European Journal of Pharmacology, 841, 57-66. http://dx.doi.org/10.1016/j.ejphar.2018.09.026

Daderman, A. M. (2005). Dr. Jekyll and Mr. Hyde: Abuse of potent benzodiazepines, exemplified by flunitrazepam, in mentally disordered male offenders. (Unpublished doctoral dissertation). Karolinska Institutet, Stockholm, Sweden.

Daderman, A. M., \& Edman, G. (2001). Flunitrazepam abuse and personality characteristics in male forensic psychiatric patients. Psychiatry Research, 103, 27-42.

Daderman, A. M., Fredriksson, B., Kristiansson, M., Nilsson, L., \& Lidberg, L. (2002). Violent behavior, impulsive decision-making, and anterograde amnesia while intoxicated with flunitrazepam and alcohol or other drugs: A case study in forensic psychiatric patients. The Journal of the American Academy of Psychiatry and the Law, 30, 238-251.

Deakin, J. B., Aitken, M. R. F., Dowson, J. H., Robbins, T. W., \& Sahakian, B. J. (2004). Diazepam produces disinhibitory cognitive effects in male volunteers. Psychopharmacology, 173, 88-97. http://dx.doi.org/10.1007/s00213-003-1695-4

Dir, A. L., Coskunpinar, A., \& Cyders, M. A. (2014). A meta-analytic review of the relationship between adolescent risky sexual behavior and impulsivity across gender, age, and race. Clinical Psychology Review, 34, 561-562. http://dx.doi.org/10.1016/j.cpr.2014.08.004 
Drechsler, R., Rizzo, P., \& Steinhausen, H. C. (2010). Decision making with uncertain reinforcement in children with attention deficit/hyperactivity disorder (ADHD). Child Neuropsychology, 16(2), 145-161.

Eppolito, A. K., France, C. P., \& Gerak, L. R. (2011). Effects of acute flunitrazepam on delay discounting in pigeons. Journal of the Experimental Analysis of Behavior, 95(2), 163-174. http://dx.doi.org/10.1901/jeab.2011.95-163

Evenden, J., \& Ko, T. (2005). The psychopharmacology of impulsive behavior in rats VIII: effects of amphetamine, methylphenidate, and other drugs on responding maintained by a fixed consecutive number avoidance schedule. Psychopharmacology, 180, 294-305.

Ferreri, M. C., Gutierrez, M. L., \& Gravielle, M. C. (2015). Tolerance to the sedative and anxiolytic effects of diazepam is associated with different alterations of $\mathrm{GABA}_{\mathrm{A}}$ receptors in rat cerebral cortex. Neuroscience, 310(3), 152-162. http://dx.doi.org/10.1016/j.neuroscience.2015.09.038

Fischer, B. D., Atack, J. R. Platt, D. M., Reynolds, D. S., Dawson, G. R., \& Rowlett, J. K., (2010). Contribution of the $\mathrm{GABA}_{\mathrm{A}}$ receptors containing $\alpha 3$ subunits to the therapeuticrelated and side effects of benzodiazepine-type drugs in monkeys. Psychopharmacology, 215(2), 311-319. http://dx.doi.org/10.1007/s00213-010-2142-y

Ford, C., \& Law, F. (2014). Guidance for the use and reduction of misuse of benzodiazepines and other hypnotics and anxiolytics in general practice. A Report for Substance Misuse Management in General Practice. Retrieved from: http://www.smmgp.org.uk/download/guidance/guidance025.pdf 
Forder, L. \& Dyson, B. J. (2016). Behavioural and neural modulation of win-stay but not loseshift strategies as a function of outcome value in rock, paper, scissors. Scientific Reports, 6 , 33809. http://dx.doi.org/10.1038/srep33809

Galdieri, D. A. (2018). Delay discounting and cannabinoid enzyme inhibitors. (Unpublished master's thesis). West Virginia University, Morgantown, West Virginia.

Gravielle, M. C. (2016). Activation-induced regulation of $\mathrm{GABA}_{\mathrm{A}}$ receptors: Is there a link with the molecular basis of benzodiazepine tolerance? Pharmacological Research, 109, 92-100. https://doi.org/10.1016/j.phrs.2015.12.030

Green, L. \& Myerson, J. (2014). How many impulsivities? A discounting perspective. Journal of the Experimental Analysis of Behavior, 99(1), 3-13. http://dx.doi.org/10.1002/jeab.1

Griffin, C. E., Kaye, A. M., Bueno, F. R., \& Kaye, A. D. (2013). Benzodiazepine pharmacology and central nervous system-mediated effects. The Ochsner Journal, 13, 214-223.

Gross, P. L. (1992). Treatment of benzodiazepine overdose with flumazenil. The flumazenil in benzodiazepine intoxication multicenter study group. Clinical Therapeutics, 14(6), 978-996.

Hart, K. L., Brown, H. E., Roffman, J. L., \& Roy, H. P. (2019). Risk tolerance measured by probability discounting among individuals with primary mood and psychotic disorders. Neuropsychology, 33(3), 417-426. http://dx.doi.org/10.1037/neu0000506

Hastjarjo, T., Silberberg, A., \& Hursh, S. R. (1990). Risky choice as a function of amount and variance in food supply. Journal of the Experimental Analysis of Behavior, 53(1), 155-161. http://dx.doi.org/10.1901/jeab.1990.53-155

Hayashi, Y., Fessler, H. J., Friedel, J. E., Foreman, A. M., \& Wirth, O. (2018). The roles of delay and probability discounting in texting while driving: Toward the development of a 
translational scientific program. Journal of the Experimental Analysis of Behavior, 110(2), 229-242. http://dx.doi.org/10.1002/jeab.460

Hayashi, Y., Miller, K., Foreman, A. M., Wirth, O. (2016). A behavioral economic analysis of texting while driving: Delay discounting processes. Accident Analysis \& Prevention, 97, 132-140. http://dx.doi.org/10.1016/j.aap.2016.08.028

Hood, S. D., Norman, A, Hince, D. A., Melichar, J. K., \& Hulse, G. K. (2012). Benzodiazepine dependence and its treatment with low dose flumazenil. British Journal of Clinical Pharmacology, 77(2), 285-294. https://dx.doi.org/10.1111/bcp.12023

Huskinson, S. A., \& Anderson, K. G. (2012). Effects of acute and chronic administration of diazepam on delay discounting in Lewis and Fischer 344 rats. Behavioural Pharmacology, $23,314-330$.

Hutchinson, M. A., Smith, P. F., \& Darlington, C. L. (1996). The behavioural and neuronal effects of the chronic administration of benzodiazepine anxiolytic and hypnotic drugs. Progress in Neurobiology, 49(1), 73-97.

Islas-Preciado, D., Wainwright, S. R., Sniegocki, J., Lieblich, S. E., Yagi, S., Floresco, S. B., \& Galea, L. A. M. (2020). Risk-based decision-making in rats: Modulation by sex and amphetamine. Hormones and Behavior, 125. https://doi.org/10.1016/j.yhbeh.2020.104815

Jansen, M., Rabe, H., Stehle, A. Dieler, S., Debus, F., Dannhardt, G., Akabas, M. H., \& Luddens, H. (2008). Journal of Medicinal Chemistry, 51(15), 4430-4448. https://dx.doi.org/10.1021/jm701562x

Jentsch, J. D., Woods, J. A., Groman, S. M., \& Seu, E. (2010). Behavioral characteristics and neural mechanisms mediating performance in a rodent version of the balloon analog risk task. Neuropsychopharmacology, 35, 1797-1806 
Johnson, B. \& Streltzer, J. (2013). Risks associated with long-term benzodiazepine use. American Family Physician, 88(4), 224-225.

Johnston, G. A. R. (2013). Advantages of an antagonist: bicuculline and other GABA antagonists. British Journal of Pharmacology, 169, 328-336. http://dx.doi.org/10.1111.bph.12127

Jupp, B., Caprioli, D., Saigal, N., Reverte, I., Shrestha, S., Cumming, P., Everitt, B. J., ...Dalley, J. W. (2013). Dopaminergic and GABA-ergic markers of impulsivity in rats: Evidence for anatomical localization in ventral striatum and prefrontal cortex. European Journal of Neuroscience, 37, 1519-1528.

Kaiser Permanente. (2019). Benzodiazepine and Z-Drug Safety Guidelines. Retrieved from https://wa.kaiserpermanente.org/static/pdf/public/guidelines/benzo-zdrug.pdf

Keeney, R. L., \& Raiffa, H. (1993). Decisions with multiple objectives: Preferences and value. Cambridge University Press.

Kim, Y. T., Lee, K., \& Lee, S. J. (2009). Deficit in decision-making in chronic, stable schizophrenia: From a reward and punishment perspective. Psychiatry Investigation, 6(1), 26-33. https://dx.doi.org/10.4306/pi.2009.6.1.26

Kyonka, E. G. E. \& Schutte, N. S. (2018). Probability discounting and gambling: a metaanalysis. Addiction, 113, 2173-2181. http://dx.doi.org/10.1111/add.14397

Lane, S. D., Cherek, D. R., \& Nouvion, S. O. (2008). Modulation of human risky decision making by flunitrazepam. Psychopharmacology, 196, 177-188. http://dx.doi.org/10.1007/s00213-007-0951-4 
Lane, S. D., Tcheremissine, O. V., Lieving, L. M., Nouvion, S. Cherek, D. R. (2005). Acute effects of alprazolam on risky decision making in humans. Psychopharmacology, 181, 364373. http://dx.doi.org/10.1007/s00213-005-2265-8.

Leung, S. Y. (2011). Benzodiazepines, opioids and driving: An overview of the experimental research. Drug and Alcohol Review, 30, 281-286. http://dx.doi.org/10.111/j.14653362.2011.00311.x

Levy, H. C., Katz, B. W., Das, A., Stevens, M. C., \& Tolin, D. F. (2019). An investigation of delay and probability discounting in hoarding disorder. Journal of Psychiatric Research, 109, 89-95. http://dx.doi.org/10.1016/j.jpsychires.2018.11.019

Lissek, S., Golisch, A., Glaubitz, B. \& Tegenthoff, M. (2017). The GABAergic system in prefrontal cortex and hippocampus modulates context-related extinction learning and renewal in humans. Brain Imaging and Behavior, 11, 1885-1900. http://dx.doi.org/10.1007/s11682-016-9662-y

Maguire, D. R., Li, J., \& France, C. P. (2012). Impulsivity and drugs of abuse: a juice-reinforced operant procedure for determining within-session delay discounting functions in rhesus monkeys. Journal of Pharmacological and Toxicological Methods, 66(3), 264-269. http://dx.doi.org/10.1016/j.vascn.2012.08.168

Manzo, L., Donaire, R., Sabariego, M., Papini, M. R., \& Torres, C. (2015). Anti-anxiety selfmedication in rats: Oral consumption of chlordiazepoxide and ethanol after reward devaluation. Behavioural Brain Research, 278, 90-97. https://dx.doi.org/10.1016/j.bbr.2014.09.017 
McMillan, D. E., \& Leander, J. D. (1978). Chronic chlordiazepoxide and pentobarbital interactions on punished and unpunished behavior. The Journal of Pharmacology and Experimental Therapeutics, 207(2), 515-520.

Mczek, K. A., \& Barry, H. (1977). Comparison of the effects of alcohol, chlordiazepoxide, and delta9-tetrahydrocannabinol on intraspecies aggression in rats. Advances in Experimental Medicine and Biology, 85, 251-264.

Mick, I., Ramos, A. C., Myers, J., Stokes, P. R., Chandrasakera, S., Erritzoe, D., Mendez, M. A., Gunn, R. N., Rabiner, E. A., Searle, G. E., Galduroz, J. C. F., Waldman, A. D., BowdenJames, H., Clark, L., Nutt, D. J., \& Lingford-Hughes, A. R. (2017). Evidence for GABAA receptor dysregulation in gambling disorder: Correlation with impulsivity. Addiction Biology, 22(6), 1601-1609. https://dx.doi.org/10.1111/adb.12457

Mitchell, M. R., Vokes, C. M., Blankenship, A. L., Simon, N. W., \& Setlow, B. (2011). Effects of acute administration of nicotine, amphetamine, diazepam, morphine, and ethanol on risky decision-making in rats. Psychopharmacology, 218(4), 703-712. http://dx.doi.org/10.1007/s00213-011-2363-8

Mobini, S., Chiang, T. J., Bradshaw, C. M., \& Szabadi, E. (2000). Effects of central 5hydroxytryptamine depletion on sensitivity to delayed and probabilistic reinforcement. Psychopharmacology, 152(4), 390-397.

Montes, D. R., Stopper, C. M., \& Floresco, S. B. (2015). Noradrenergic modulation of risk/reward decision making. Psychopharmacology, 232, 2681-2696. http://dx.doi.org/10.1007/s00213-015-3904-3

Moreira, P. S., Macoveanu, J., Marques, P., Coehlo, A., Magalhaes, R., Siebner, H. R., Soares, J. M., Sousa, N., \& Morgado, P. (2019). Altered response to risky decisions and reward in 
patients with obsessive-compulsive disorder. Journal of Psychiatry and Neuroscience, 1;45(2), 98-107. http://dx.doi.org/10.1503/jpn.180226

Murphy, E. R., Fernando, A. B. P., Urcelay, G. P., Robinson, E. S. J., Mar, A. C., Theobald, E. H., Dalley, J. W., \& Robbins, T. W. (2010). Impulsive behavior induced by both NMDA receptor antagonism and $\mathrm{GABA}_{\mathrm{A}}$ receptor activation in rat ventromedial prefrontal cortex. Psychopharmacology, 219, 401-410. http://dx.doi.org/10.1007/s00213-011-2572-1

National Institute on Drug Abuse. (2018). Benzodiazepines and Opioids. Retrieved from https://www.drugabuse.gov/drugs-abuse/opioids/benzodiazepines-opioids

Nordin, C., \& Sjodin, I. (2007). CSF cholecystokinin, gamma-aminobutyric acid and neuropeptide $\mathrm{Y}$ in pathological gamblers and healthy controls. Journal of Neural Transmission, 114(4), 499-503. http://dx.doi.org/10.1007/s00702-006-0593-4

O’Neal, Glenn. (2012). Study finds increasing use, and misuse, of benzodiazepines. Retrieved from https://www.psychiatry.org/newsroom/news-releases/study-finds-increasing-use-andmisuse-of-benzodiazepines

Orriols, L., Philip, P., Moore, N. Castot, A. Gadegeku, B., Delorme, B., Mallaret, M., \& Lagarde, E. (2011). Benzodiazepine-like hypnotics and the associated risk of road traffic accidents. Clinical Pharmacology and Therapeutics, 89(4), 595-601. http://dx.doi.org/10.1038/clpt.2011.3

Ozga, J. E., \& Anderson, K. G. (2018). Differential effects of $d$-amphetamine and atomoxetine on risk-based decision-making of Lewis and Fischer 344 rats. Manuscript submitted for publication. 
Paine, T. A., Cook, E. K., \& Lowes, D. C. (2015). Effects of chronic inhibition of GABA synthesis on attention and impulse control. Pharmacology, Biochemistry, and Behavior, 135, 97-104. http://dx.doi.org/10.1016/j.pbb.2015.05.019

Paine, T. A., Slipp, L. E., \& Carlezon, W. A. (2011). Schizophrenia-like attentional deficits following blockade of prefrontal cortex GABAA receptors. Neuropsychopharmacology, 36, 1703-1713. http://dx.doi.org/10.1038/npp.2011.51

Pajunen, T., Vuori, E., Vincenzi, F. F., Lillsunde, P., Smith, G., \& Lunetta, P. (2017). Unintentional drowning: Role of medicinal drugs and alcohol. BMC Public Health, 17(388). http://dx.doi.org/10.1186/s12889-017-4306-8

Perry, J. L., Stairs, D. J., \& Bardo, M. T. (2008). Impulsive choice and environmental enrichment: Effects of d-amphetamine and methylphenidate. Behavioural Brain Research, 193(1), 48-45. https://dx.doi.org/10.1016/j.bbr.2008.04.019

Piantadosi, P. T., \& Floresco, S. B. (2014). Prefrontal cortical GABA transmission modulates discrimination and latent inhibition of conditioned fear: Relevance for schizophrenia. Neuropsychopharmacology, 39, 2473-2484. http://dx.doi.org/10.1038/npp.2014.99

Piantadosi, P. T., Khayambashi, S., Schluter, M. G., \& Kutarna, A. (2016). Perturbations in reward-related decision-making induced by reduced prefrontal cortical GABA transmission: Relevance for psychiatric disorders. Neuropharmacology, 101, 279-290. http://dx.doi.org/10.1016/j.neuropharm.2015.10.007

Pitts, R. C., Buda, D. R., Keith, J. R., Cerutti, D. T., \& Galizio, M. (2006). Chlordiazepoxide and dizocilpine, but not morphine, selectively impair acquisition under a novel repeatedacquisition and performance task in rats. Psychopharmacology, 189, 135-143. 
Potts, N. L. S. \& Krishnan, K. R. R. (1992). Long-term use of benzodiazepines. Canadian Family Physician, 38, 149-153.

Reed, P. (2018). Retention period differentially attenuates win-shift/lose-stay relative to winstay/lose-shift performance in the rat. Learning \& Behavior, 46, 60-66. https://dx.doi.org/10.3758/s13420-01709289-7

Reynolds, B., Richards, J. B., Dassinger, M., \& de Wit, H. (2004). Therapeutic doses of diazepam do not alter impulsive choice in humans. Pharmacology Biochemistry and Behavior, 79, 17-24. http://dx.doi.org/10.1016/j.pbb.2004.06.011

Rosenberg, H. C. \& Chiu. T. H. (1985). Time course for development of benzodiazepine tolerance and physical dependence. Neuroscience \& Biobehavioral Reviews, (9)1, 123-131. https://doi.org/10.1016/0149-7634(85)90038-7

Sannerud, C. A., Marley, R. J., Serdikoff, S. L., Alastra, A. J., Cohen, C., \& Goldberg, S. R. (1993). Tolerance to the behavioral effects of chlordiazepoxide: Pharmacological and biochemical selectivity. The Journal of Pharmacology and Experimental Therapeutics, 267(3), 1311-1320. https://doi.org/10.1016/s0031-6989(88)80669-6

Schindler, A. G., Tsutsui, K. T., \& Clark, J. J. (2014). Chronic alcohol intake during adolescence, but not adulthood, promotes persistent deficits in risk-based decision making. Alcohol: Clinical and Experimental Research, 38(6), 1622-1629. http://dx.doi.org/10.1111/acer.12404

Schmitz, A. (2016). Benzodiazepine use, misuse, and abuse: A review. Mental Health Clinician, 6(3), 120-126. http://dx.doi.org/10.9740/mhc.2016.05.120

Schwienteck, K. L., Li, G., Poe, M. M., Cook, J. M., Banks, M. L., \& Negus, S. S. (2017). Abuse-related effects of subtype-selective $\mathrm{GABA}_{\mathrm{A}}$ receptor positive allosteric modulators in 
an assay of intracranial self-stimulation in rats. Psychopharmacology, 234(14), 2091-2101. https://dx.doi.org/10.1007/s00213-017-4615-8

Shurman, B., Horan, W. P., \& Nuechterlein, K. H. (2005). Schizophrenia patients demonstrate a distinctive pattern of decision-making impairment on the Iowa Gambling Tasks. Schizophrenia Research, 72, 215-224. https://dx.doi.org/10.1016/j.schres.2004.03.020

Sidman, M. (1960). Tactics of scientific research: Evaluating experimental data in psychology. Basic Books.

Sigel, E., \& Steinmann, M. E. (2012). Structure, function, and modulation of GABA A receptors. The Journal of Biological Chemistry, 287(48), 40224-40231. http://dx.doi.org/10.1074/jbc.R112.386664

Simoes, S., Amorim, J., \& Machado, A. (2010). Intense lorazepam-induced sexual arousal. Progress in Neuro-Psychopharmacology and Biological Psychiatry, 34(1), 236-237.

St. Onge, J. R., Chiu, Y. C., \& Floresco, S. B. (2010). Differential effects of dopaminergic manipulations on risky choice. Psychopharmacology. 211(2), 209-221. http://dx.doi.org/10.1007/s00213-010-1883-y

St. Onge, J. R. \& Floresco, S. B. (2009). Dopaminergic modulation of risk-based decision making. Neuropsychopharmacology, 34, 681-697. http://dx.doi.org/10.1038/npp.2008.121

Stopper, C. M. \& Floresco, S. B. (2011). Contributions of the nucleus accumbens and its subregions to different aspects of risk-based decision making. Cognitive, Affective, and Behavioral Neuroscience, 11, 97-112. http://dx.doi.org/10.3758/s13415-010-0015-9

Substance Abuse and Mental Health Services Administration, Center for Behavioral Health Statistics and Quality. (2012). The TEDS Report: Admissions Reporting Benzodiazepine and Narcotic Pain Reliever Abuse at Treatment Entry. Rockville, MD. 
Thapa, R., \& Gruber, A. J. (2018). Lesions of ventrolateral striatum eliminate lose-shift but not win-stay behavior in rats. Neurobiology of Learning and Memory, 155, 446-451. https://dx.doi.org/10.1016/j.nlm.2018.08.022

Tom, S. M., Fox, C. R., Thepel, C., \& Poldrack, R. A. (2007). The neural basis of loss aversion in decision-making under risk. Science, 315, 515-517. https://dx.doi.org/10.1126/science.1134239

Ucha, M., Roura-Martinez, D., Contreras, A., Pinto-Rivero, S., Orihuel, J., Ambrosio, E., \& Higuera-Matas, A. (2019). Impulsive action and impulsive choice are differentially associated with gene expression variations of the $\mathrm{GABA}_{\mathrm{A}}$ receptor alfa 1 subunit and the $\mathrm{CB}_{1}$ receptor in the lateral and medial orbitofrontal cortices. Frontiers in Behavioral Neuroscience, 13(22). http://dx.doi.org/10.3389/fnbeh.2019.00022.

Van Haaren, F., \& Anderson, K. G. (1998). Avoidance of time-out from response-independent food presentation: Effects of chlordiazepoxide and buspirone. Pharmacology, Biochemistry, and Behavior, 61(2), 207-2014.

Van Haaren, F. Katon, E., \& Anderson, K. G. (1997). The effects of chlordiazepoxide on lowrate behavior are gender dependent. Pharmacology, Biochemistry, and Behavior, 58(4), 1037-1043.

Van der Sluiszen, N. N. J. J. M., Vermeeren, A., Jongen, S., Vinckenbosch, F., \& Ramaekers, J. G. (2107). Influence of long-term benzodiazepine use on neurocognitive skills related to driving performance in patient populations: A review. Pharmacopsychiatry, 50, 189-196. http://dx.doi.org/10.1055/s-0043-112755

Vinkers, C. H., Korte-Bouws, G. A. H., Toraño, J. S., Mirza, N. R., Nielsen, E., Ahring, P. K., de Jong, G. J., \& Olivier, B. (2010). The rapid hydrolysis of chlordiazepoxide to demoxepam 
may affect the outcome of chronic osmotic minipump studies. Psychopharmacology, 208, 555-562. http://dx.doi.org/101007/s00213-009-1752-8

Vinkers, C. H., \& Olivier, B. (2012). Mechanisms underlying tolerance after long-term benzodiazepine use: A future fur subtype-selecting $\mathrm{GABA}_{\mathrm{A}}$ modulators? Advances in Pharmacological Sciences, 1-19, http://dx.doi.org/10.1155/2012/416864

Wallin-Miller, K. G., Chesley, J., Castrillon, J., \& Wood, R. I. (2017). Sex differences and hormonal modulation of ethanol-enhanced risk taking in rats. Drug and Alcohol Dependence, 174, 137-144. http://dx.doi.org/10.1016/j.drugalcdep.2017.01.023

Winstanley, C. A., \& Floresco, S. B. (2016). Deciphering decision making: Variation in animal models of effort- and uncertainty-based choice reveals distinct neural circuitries underlying core cognitive processes. The Journal of Neuroscience, 36(48), 12069-12079. http://dx.doi.org/10.1523/JNEUROSCI.1713-16.2016

Yang, F. N., Pan, J. S., \& Li, X. (2016). Beta-adrenoceptor blockade abolishes atomoxetineinduced risk taking. Physiology \& Behavior, 153, 125-132. http://dx.doi.org/10.1016/j.physbeh.2015.10.032

Yates, J. R. (2019). Examining the neurochemical underpinnings of animal models of risky choice: Methodological and analytic considerations. Experimental and Clinical Psychopharmacology, 27(2), 178-201. http://dx.doi.org/10.1037/pha0000239.

Yates, J. R., Chitwood, M. R., Evans, K. E., Kappesser, J. L., Murray, C. P. Paradella-Bradley, T. A., \& Torline, B. T. (2019). Group 1 metabotropic glutamate receptor antagonists impair discriminability of reinforcer magnitude, but not risky choice, in a probability-discounting task. Behavioural Brain Research, 365, 77-81. https://doi.org/10.1016/j.bbr.2019.02.047 
Zeeb, F. D., Robbins, T. W., \& Winstanley, C. A. (2009). Serotonergic and dopaminergic modulation of gambling behavior as assessed using a novel rat gambling task. Neuropsychopharmacology, 34, 2329-2343. http://dx.doi.org/10.1038/npp.2009.62 


\section{Table 1}

Mean and SEM for omitted trials at each dose of CDP in each phase.

\begin{tabular}{|c|c|c|c|c|c|c|c|c|c|c|c|c|}
\hline \multirow[b]{3}{*}{ Phase } & \multicolumn{12}{|c|}{ Dose CDP (mg/kg) } \\
\hline & \multicolumn{2}{|c|}{ Saline } & \multicolumn{2}{|c|}{1.0} & \multicolumn{2}{|c|}{3.0} & \multicolumn{2}{|c|}{10.0} & \multicolumn{2}{|c|}{17.0} & \multicolumn{2}{|c|}{30.0} \\
\hline & $M$ & SEM & $M$ & SEM & $M$ & SEM & $M$ & SEM & $M$ & SEM & $M$ & SEM \\
\hline Acute & 0.34 & 0.18 & 0.38 & 0.15 & 0.19 & 0.11 & 0.85 & 0.51 & 25.13 & 4.73 & 42.00 & 5.82 \\
\hline Chronic & 2.43 & 0.75 & 6.04 & 2.58 & 1.29 & 0.49 & 0.15 & 0.15 & 2.67 & 1.30 & 0.10 & 0.10 \\
\hline
\end{tabular}




\section{Table 2}

Mean and SEM for acute percent larger-reinforcer choice in each block during acute drug exposure.

\begin{tabular}{|c|c|c|c|c|c|c|c|c|}
\hline \multirow[b]{3}{*}{ Block } & \multicolumn{8}{|c|}{ Dose CDP (mg/kg) } \\
\hline & \multicolumn{2}{|c|}{ Saline } & \multicolumn{2}{|c|}{1.0} & \multicolumn{2}{|c|}{3.0} & \multicolumn{2}{|c|}{10.0} \\
\hline & $M$ & $S E M$ & $M$ & SEM & $M$ & $S E M$ & $M$ & $S E M$ \\
\hline 1 & 99.48 & 0.52 & 100.0 & 0.00 & 97.92 & 1.04 & 98.44 & 1.02 \\
\hline 2 & 85.05 & 5.14 & 89.32 & 5.06 & 94.01 & 3.42 & 90.23 & 2.73 \\
\hline 3 & 33.67 & 6.91 & 61.20 & 12.18 & 71.61 & 8.09 & 72.92 & 8.22 \\
\hline 4 & 11.33 & 7.48 & 19.80 & 7.03 & 22.96 & 9.89 & 39.97 & 9.64 \\
\hline 5 & 7.63 & 3.23 & 5.21 & 3.82 & 14.58 & 8.55 & 24.61 & 11.02 \\
\hline
\end{tabular}




\section{Table 3}

Mean and SEM for area-under-the-curve (AUC), indifference points (IPS), win:stay ratios (WSRs) and lose:shift ratios (LSRs) during acute drug exposure.

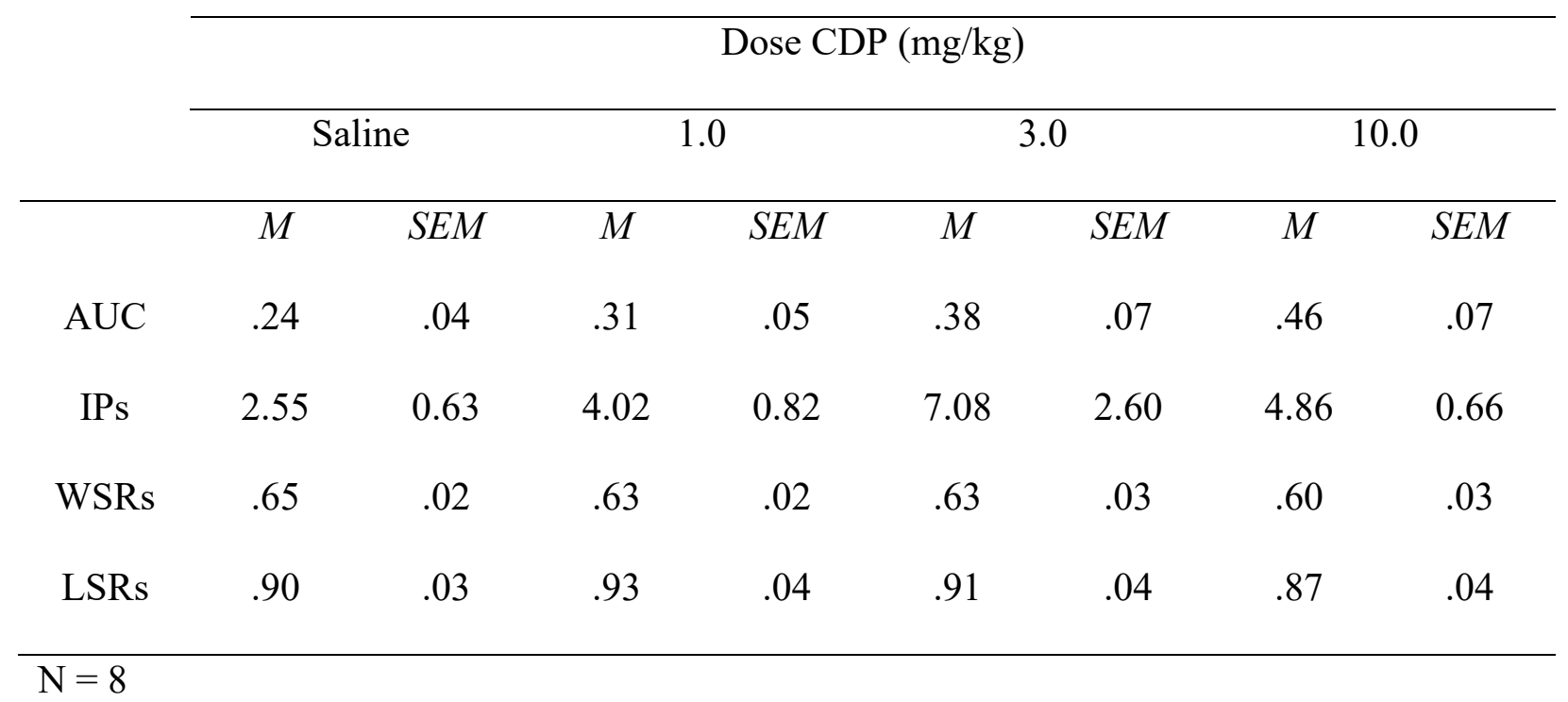




\section{Table 4}

Mean and SEM for percent larger-reinforcer choice (\% LRC), area-under-the-curve (AUC), indifference points (IPS), win:stay ratios (WSRs) and lose:shift ratios (LSRs) during the first and last five days of chronic exposure.

\section{Condition}

\begin{tabular}{ccccccc}
\hline & \multicolumn{2}{c}{ Saline } & \multicolumn{2}{c}{ First Five } & \multicolumn{2}{c}{ Last Five } \\
\hline Measure & $M$ & $S E M$ & $M$ & $S E M$ & $M$ & $S E M$ \\
\% LRC & 45.47 & 2.33 & 68.65 & 5.58 & 55.97 & 6.13 \\
AUC & .23 & .04 & .34 & .08 & .27 & .06 \\
IPs & 2.55 & 0.63 & 4.76 & 1.78 & 3.24 & 0.91 \\
WSRs & .65 & .18 & .61 & .02 & .61 & .01 \\
LSRs & .90 & .03 & .89 & .06 & .92 & .04 \\
\hline $\mathrm{N}=6$ & & &
\end{tabular}




\section{Table 5}

Mean and SEM for percent larger-reinforcer choice in each block at each dose of CDP during chronic drug exposure.

\begin{tabular}{|c|c|c|c|c|c|c|c|c|c|c|c|c|}
\hline & \multicolumn{12}{|c|}{ Dose CDP (mg/kg) } \\
\hline & \multicolumn{2}{|c|}{ Saline } & \multicolumn{2}{|c|}{1.0} & \multicolumn{2}{|c|}{3.0} & \multicolumn{2}{|c|}{10.0} & \multicolumn{2}{|c|}{17.0} & \multicolumn{2}{|c|}{30.0} \\
\hline Block & $M$ & $S E M$ & $M$ & SEM & $M$ & $S E M$ & $M$ & SEM & $M$ & $S E M$ & $\bar{M}$ & SEM \\
\hline 1 & 100.00 & 0.00 & 98.96 & 1.04 & 98.96 & 1.04 & 100.00 & 0.00 & 98.96 & 1.04 & 100.00 & 0.00 \\
\hline 2 & 80.90 & 10.13 & 83.33 & 7.85 & 92.71 & 6.13 & 97.92 & 1.32 & 97.92 & 1.32 & 96.25 & 2.50 \\
\hline 3 & 34.03 & 12.52 & 17.71 & 6.13 & 41.67 & 7.16 & 67.71 & 12.22 & 66.67 & 9.08 & 82.50 & 9.35 \\
\hline 4 & 12.50 & 7.76 & 2.08 & 1.32 & 8.33 & 4.47 & 9.38 & 5.98 & 15.63 & 10.92 & 20.00 & 13.02 \\
\hline 5 & 2.08 & 1.42 & 1.04 & 1.04 & 4.17 & 2.64 & 9.38 & 4.19 & 2.08 & 2.08 & 15.00 & 7.29 \\
\hline
\end{tabular}




\section{Table 6}

Mean and SEM for area under the curve (AUC), indifference points (IPs), win:stay ratios (WSRs), and lose:shift ratios (LSRs) at each dose of CDP during chronic drug exposure.

\section{Dose CDP (mg/kg)}

Saline

$1.0 \quad 3.0$

10.0

17.0

30.0

\begin{tabular}{ccccccccccccc}
\hline Measure & $M$ & SEM & $M$ & SEM & $M$ & SEM & $M$ & SEM & $M$ & SEM & $M$ & SEM \\
AUC & .22 & .06 & .13 & .02 & .24 & .03 & .30 & .04 & .31 & .05 & .31 & .06 \\
IPs & 2.37 & 0.82 & 1.53 & 0.22 & 2.54 & 0.47 & 3.78 & 0.60 & 3.96 & .86 & 5.95 & 1.73 \\
WSRs & .59 & .01 & .65 & .02 & .6. & .04 & .54 & .04 & .57 & .03 & .62 & .06 \\
LSRs & .91 & .04 & .76 & .06 & .85 & .09 & .84 & .05 & .87 & .09 & .87 & .10 \\
\hline $\mathrm{N}=6$ & & & & & & & & & & & &
\end{tabular}




\section{Figure 1}

Group means and SEM for percent larger-reinforcer choice as a function of probability of delivery during acute drug exposure.

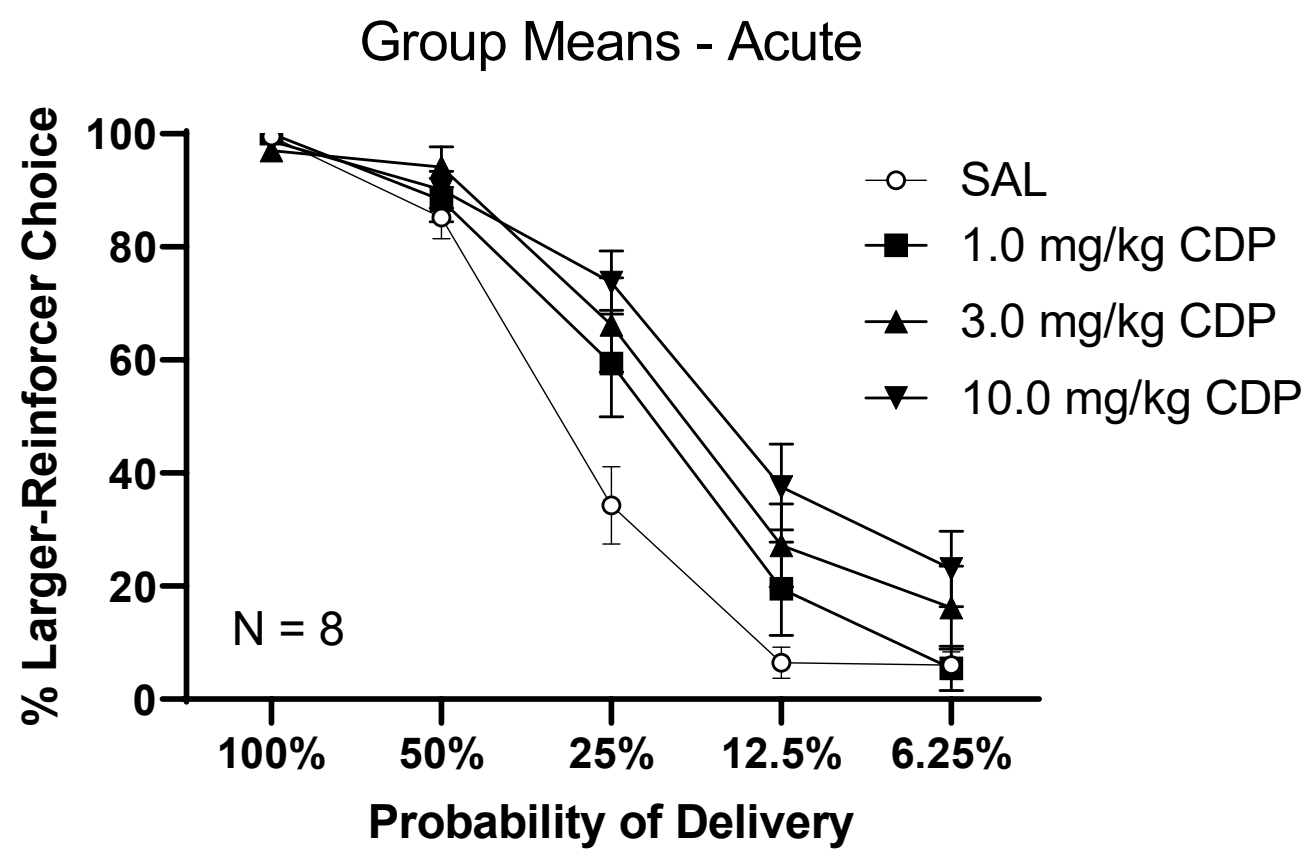

Note. Percent larger-reinforcer choice in the third (25\%) block was significantly higher for $1.0(p$

$=.01), 3.0(p<.01)$, and $10.0(p<.01) \mathrm{mg} / \mathrm{kg}$ CDP relative to saline. The acute 17.0 and 30.0 $\mathrm{mg} / \mathrm{kg}$ doses were excluded from analysis due to generalized response disruption. 


\section{Figure 2}

Individual means and SEM for percent larger-reinforcer choice as a function of probability of delivery during acute drug exposure.

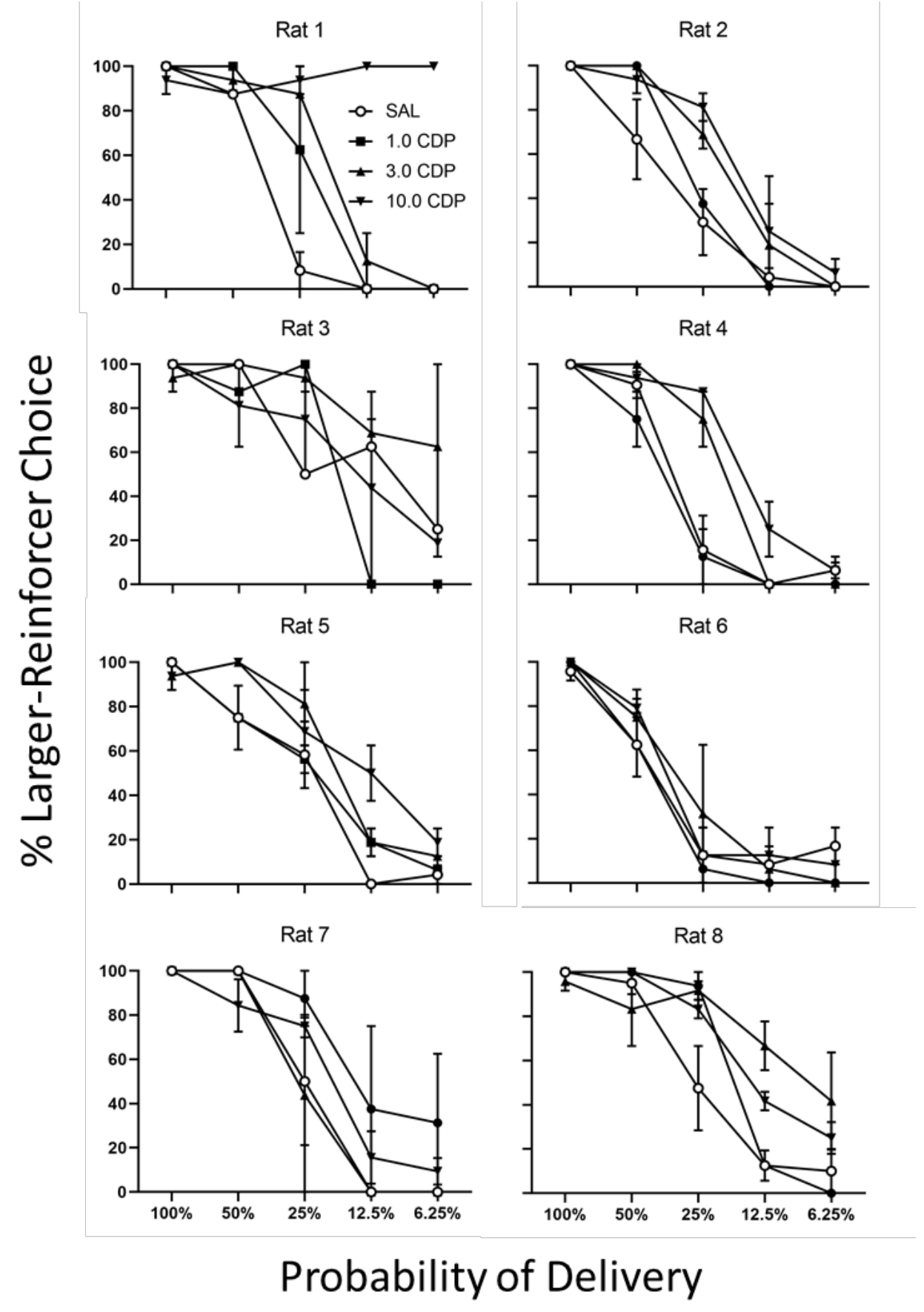




\section{Figure 3}

Means and SEM for overall (full session) percent larger-reinforcer choice as a function of dose during acute drug exposure.

\section{Acute Dose-Response Function}

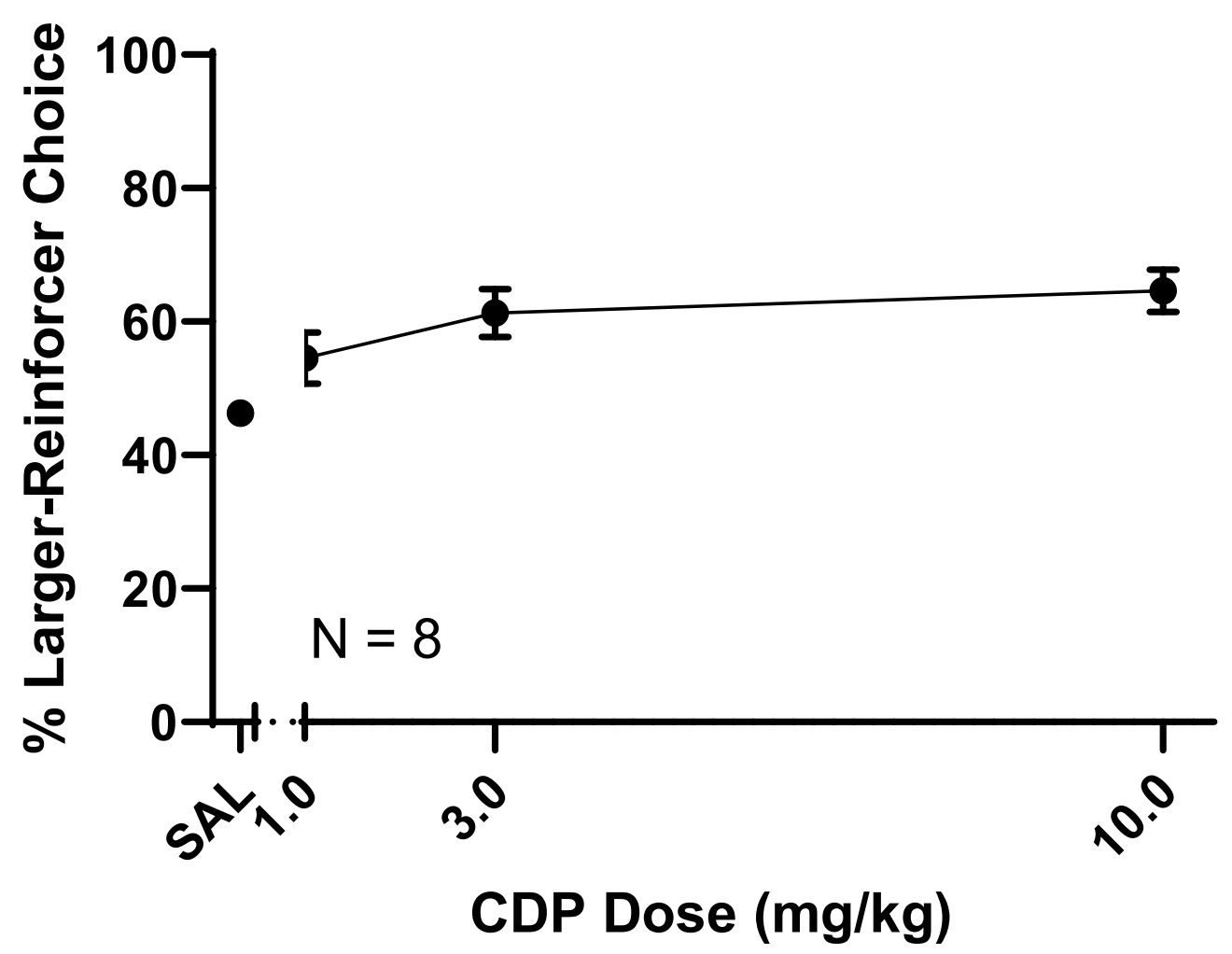

Note. Overall percent larger-reinforcer choice was significantly higher relative to saline under $3.0(p<.01)$ and $10.0(p=.02) \mathrm{mg} / \mathrm{kg}$ CDP. 


\section{Figure 4}

Means and SEM for area under the curve as a function of dose during acute drug exposure.

\section{Acute Dose-Response Function}

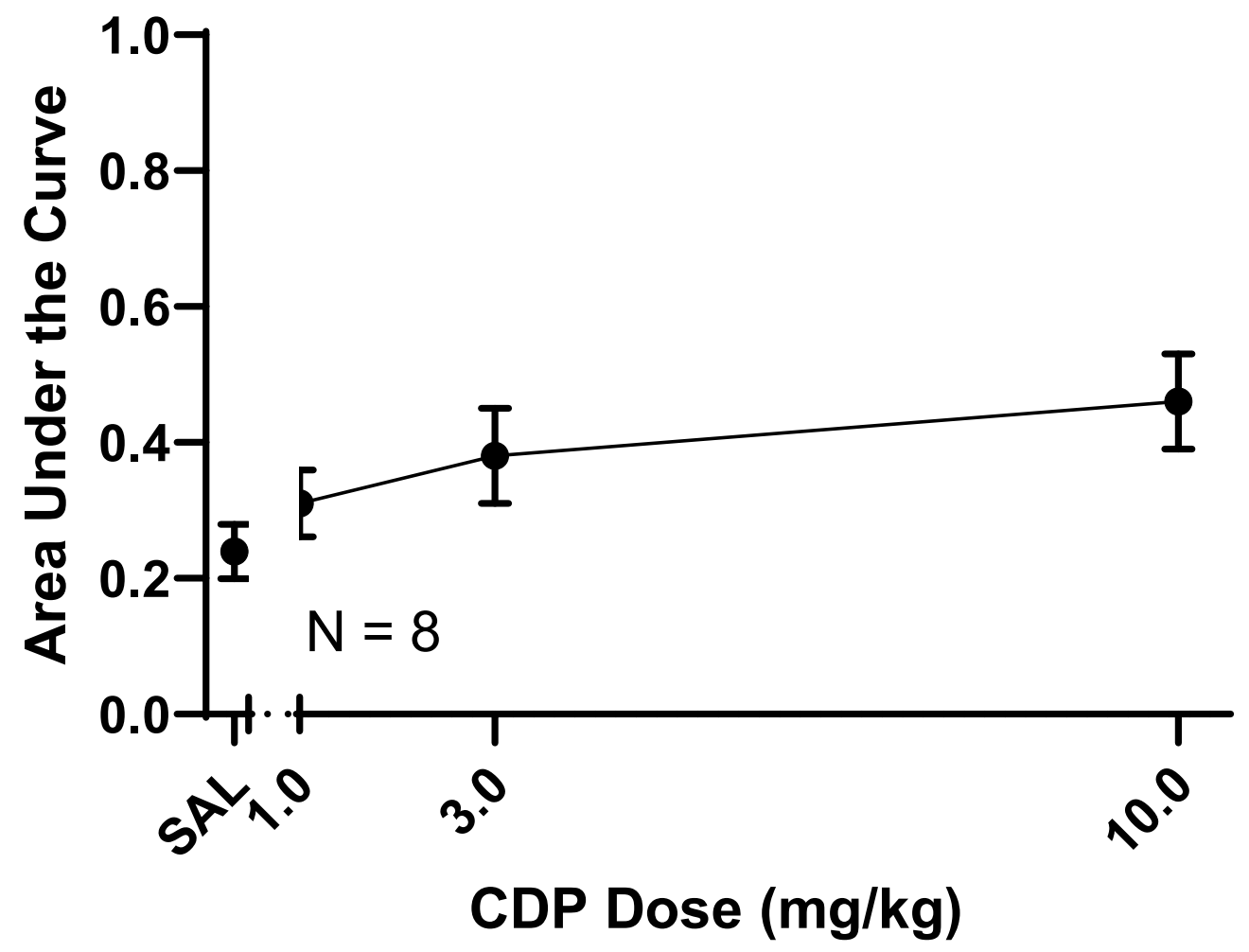

Note. Area under the curve was significantly higher relative to saline at $3.0(p=.01)$ and $10.0(p$

$=.04) \mathrm{mg} / \mathrm{kg} \mathrm{CDP}$. 


\section{Figure 5}

Mean and SEM for percent larger-reinforcer choice as a function of probability of delivery for acute saline, first five days of initial chronic drug exposure, and last five days of initial chronic drug exposure.

\section{Larger Reinforcer Choice}

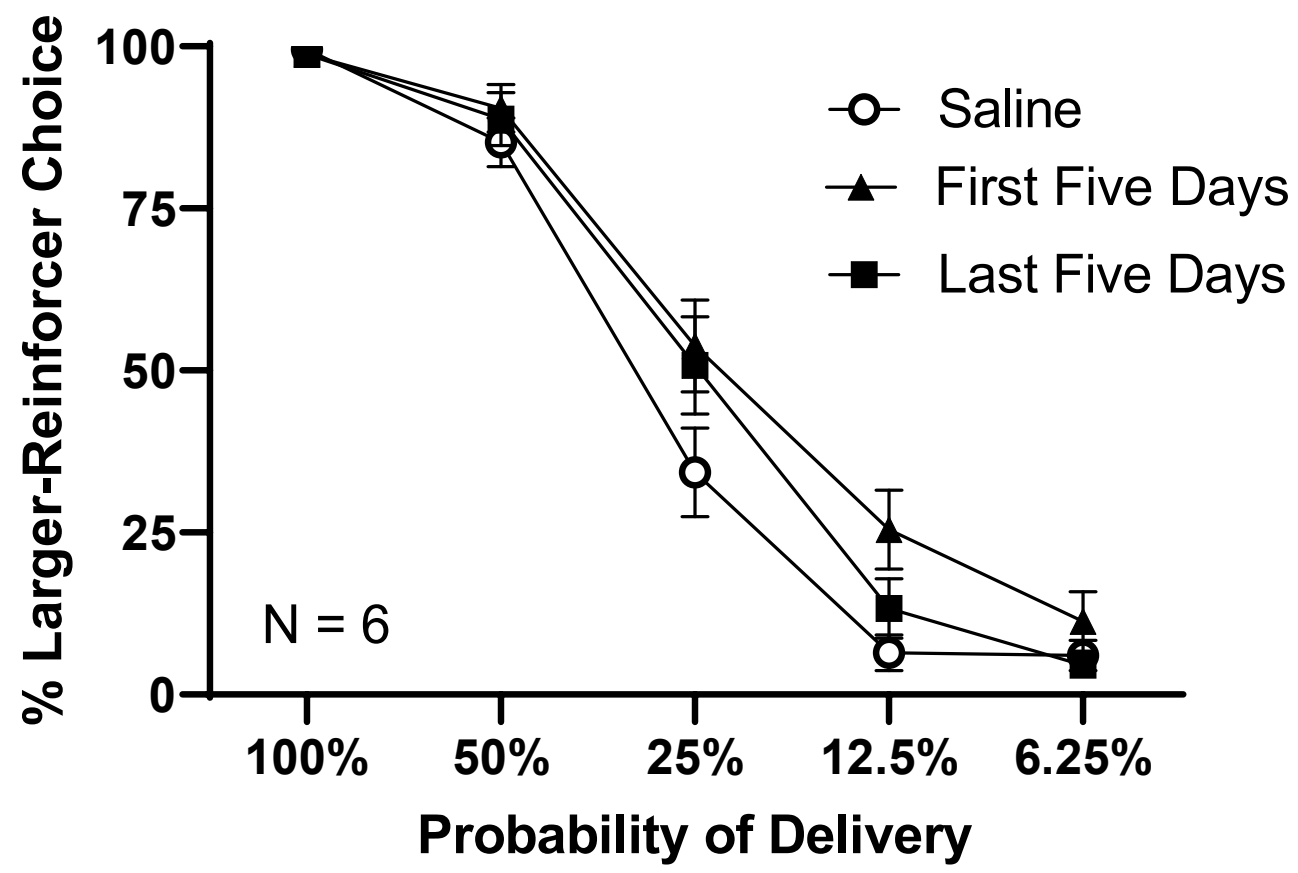

Note. Percent larger-reinforcer choice was significantly higher than saline during the first five days of chronic drug exposure $(p=.04)$, but not the last five days. 


\section{Figure 6}

Mean and SEM for indifference points during the first and last five days of chronic drug exposure, as well as for baseline saline.

\section{Indifference Points}

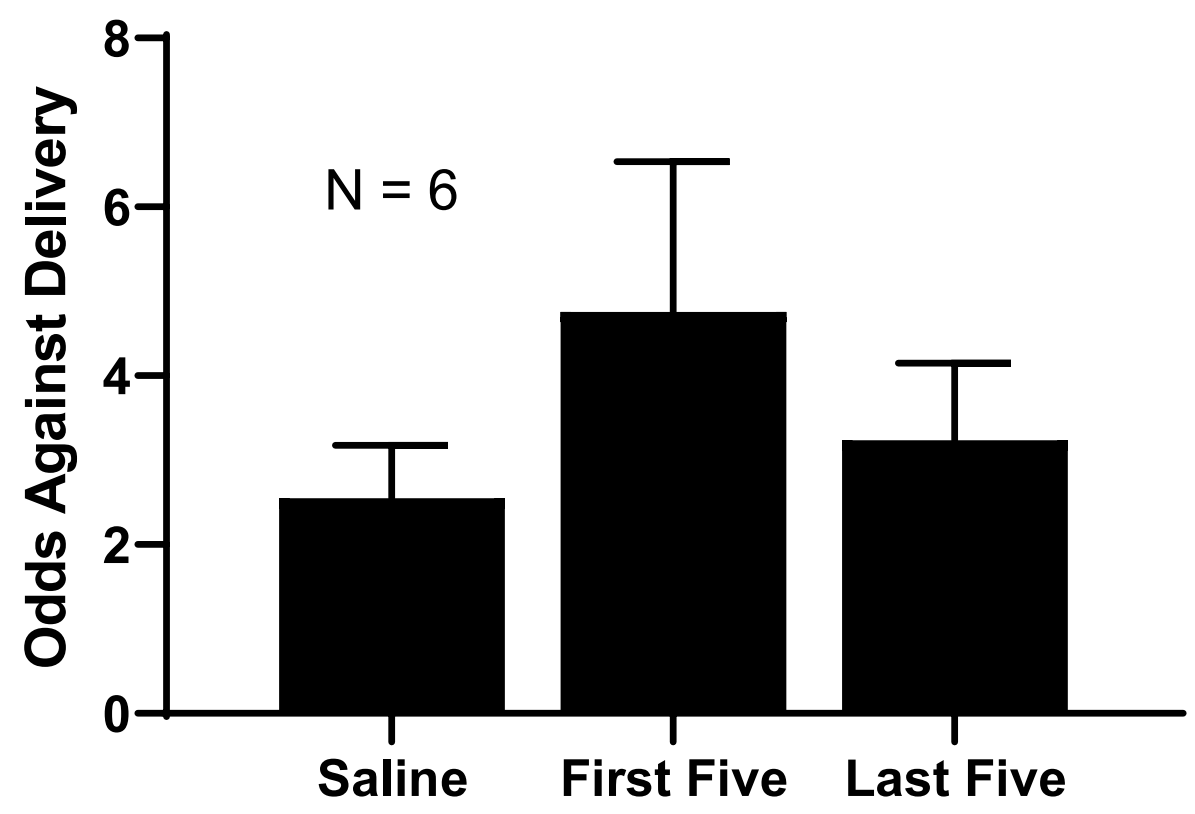




\section{Figure 7}

Means and SEM for area under the curve during the first and last five days of chronic drug exposure, as well as for baseline saline.

\section{Area Under the Curve}

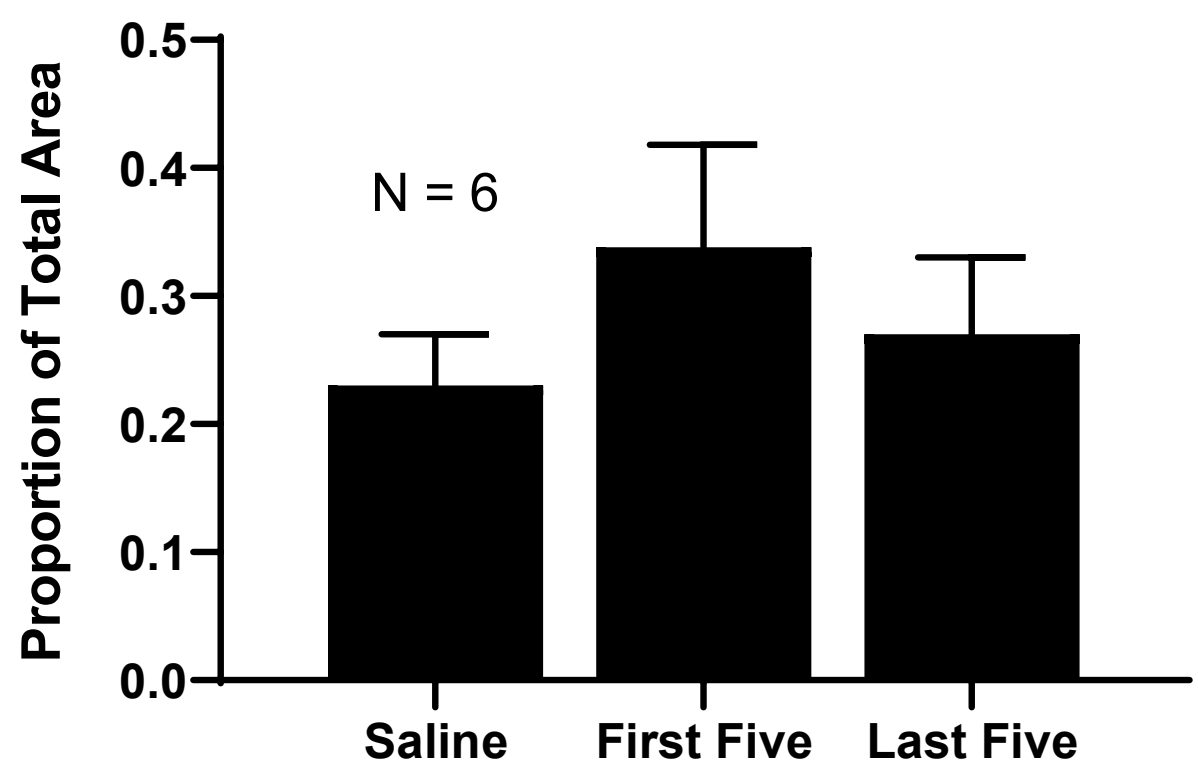




\section{Figure 8}

Means and SEM for win:stay ratios and lose:shift ratios during the first and last five days of chronic drug exposure, as well as for baseline saline.

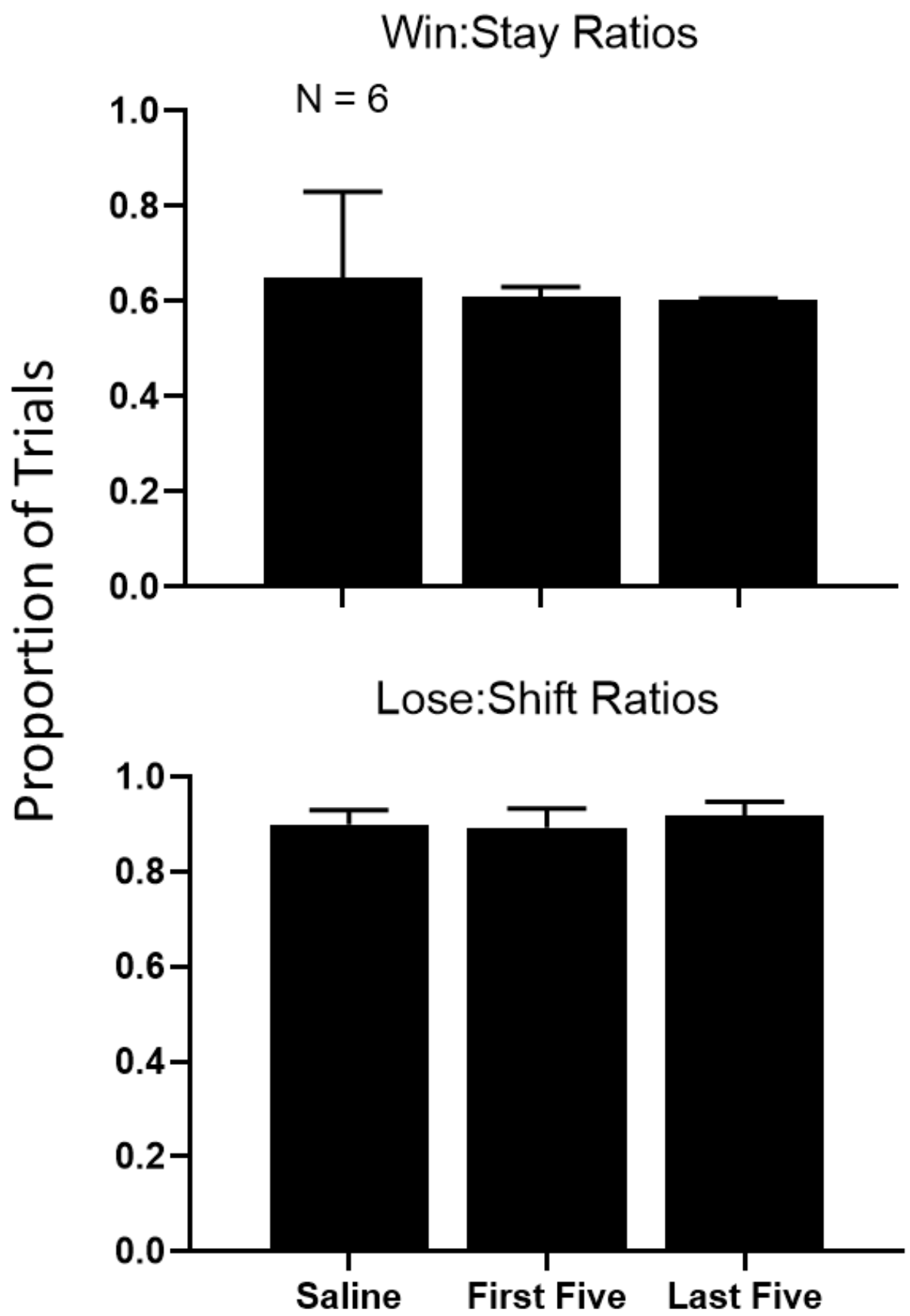




\section{Figure 9}

Group means and SEM for percent larger-reinforcer choice as a function of probability of delivery during chronic drug exposure.

\section{Group Means - Chronic}

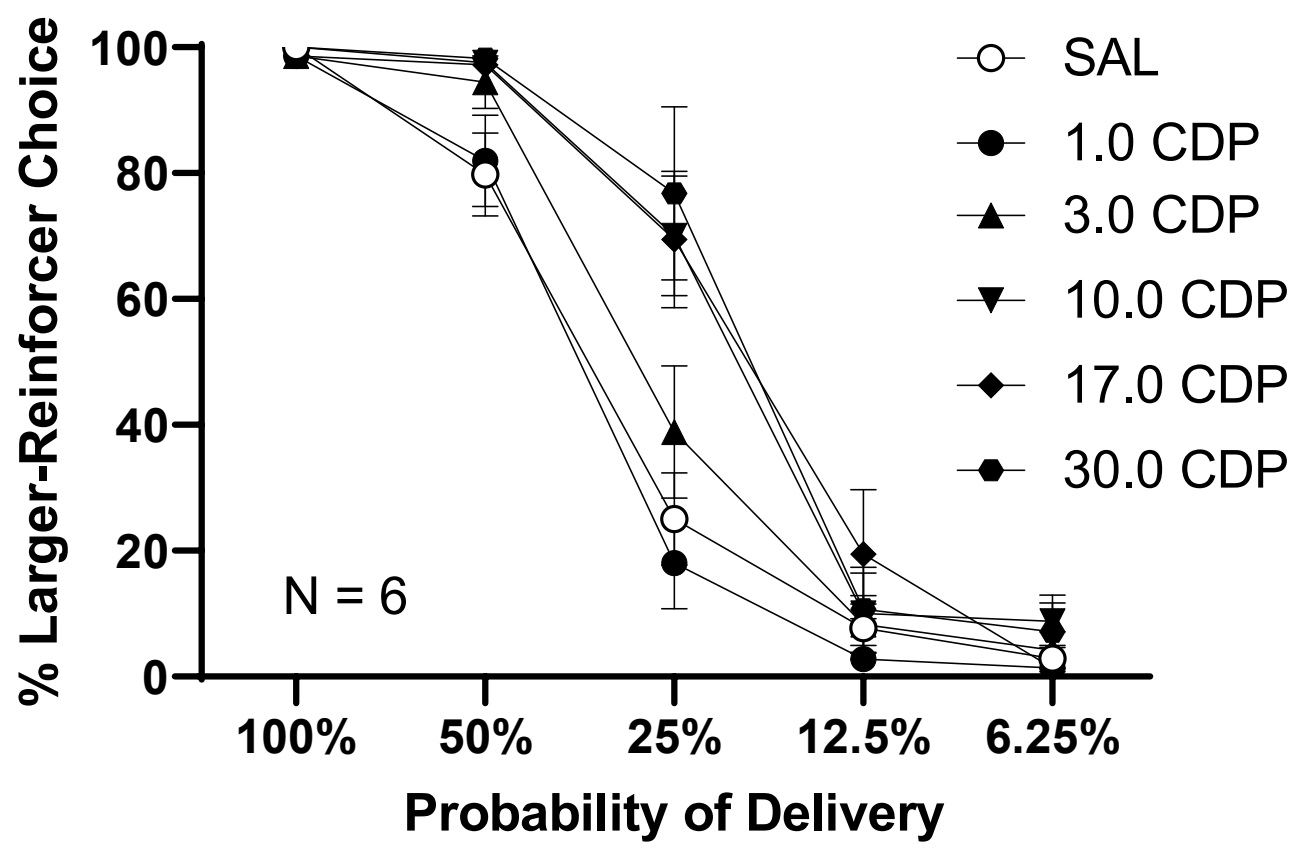

Note. Percent larger-reinforcer choice was higher in the third $(25 \%)$ block relative to saline at the $10.0(p<.01), 17.0(p=.03)$, and $30.0(p<.01) \mathrm{mg} / \mathrm{kg}$ doses of CDP. 


\section{Figure 10}

Means and SEM for percent larger-reinforcer choice as a function of probability of delivery for individual rats during chronic drug exposure.

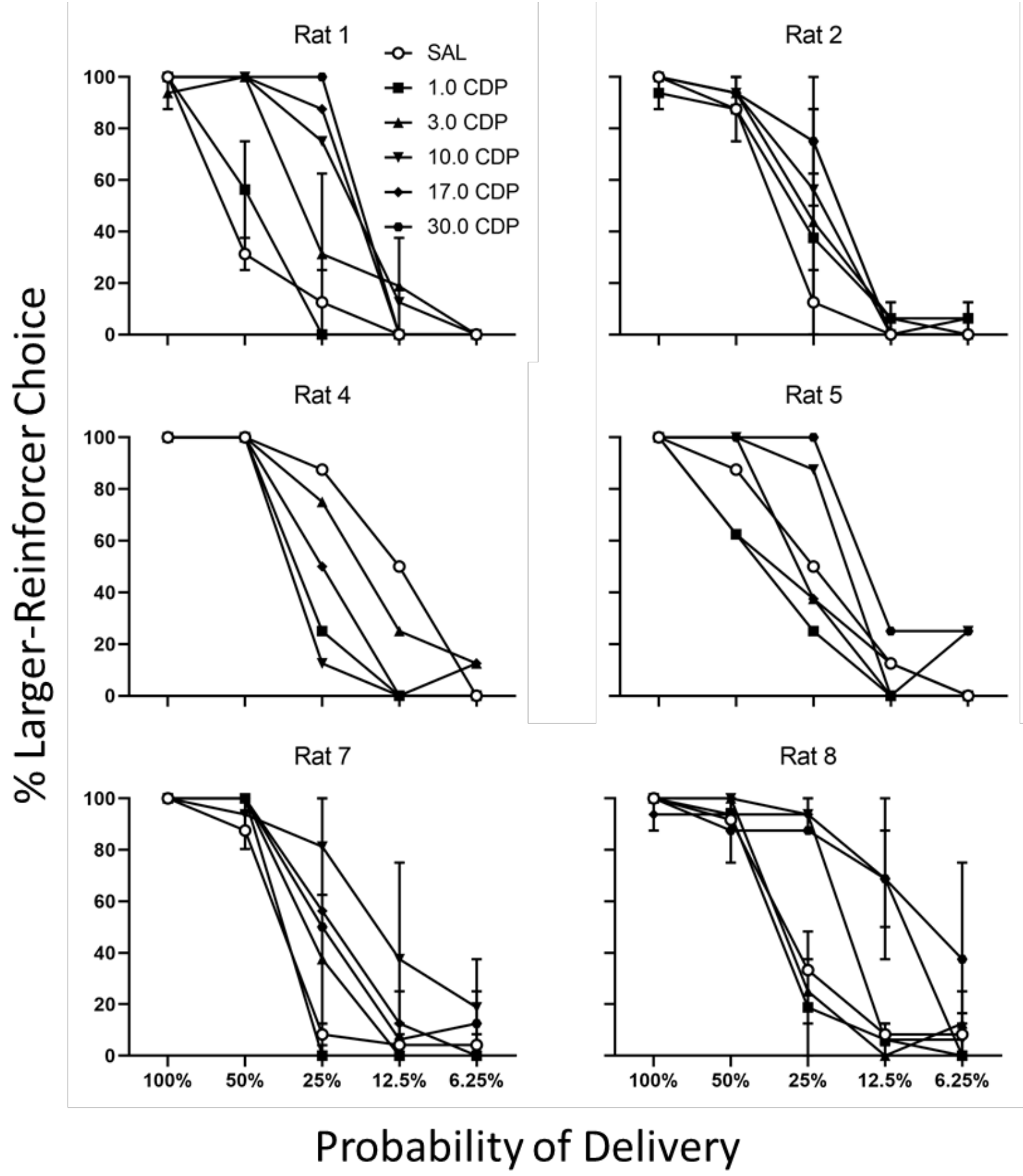




\section{Figure 11}

Means and SEM for area under the curve as a function of dose during chronic drug exposure.

\section{Dose-Response Function}

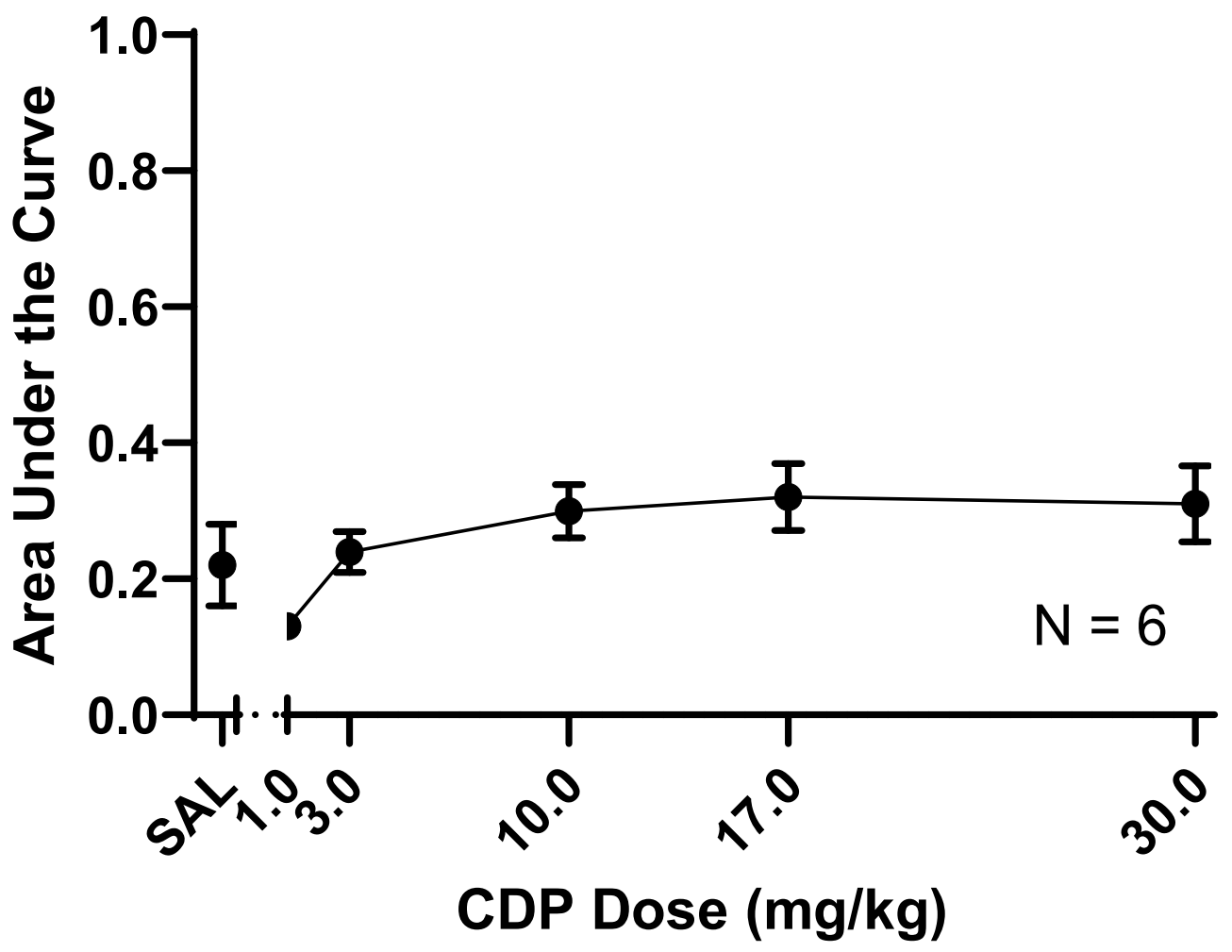




\section{Figure 12}

Means and SEM for indifference points as a function of dose during chronic drug exposure.

\section{Dose-Response Function}

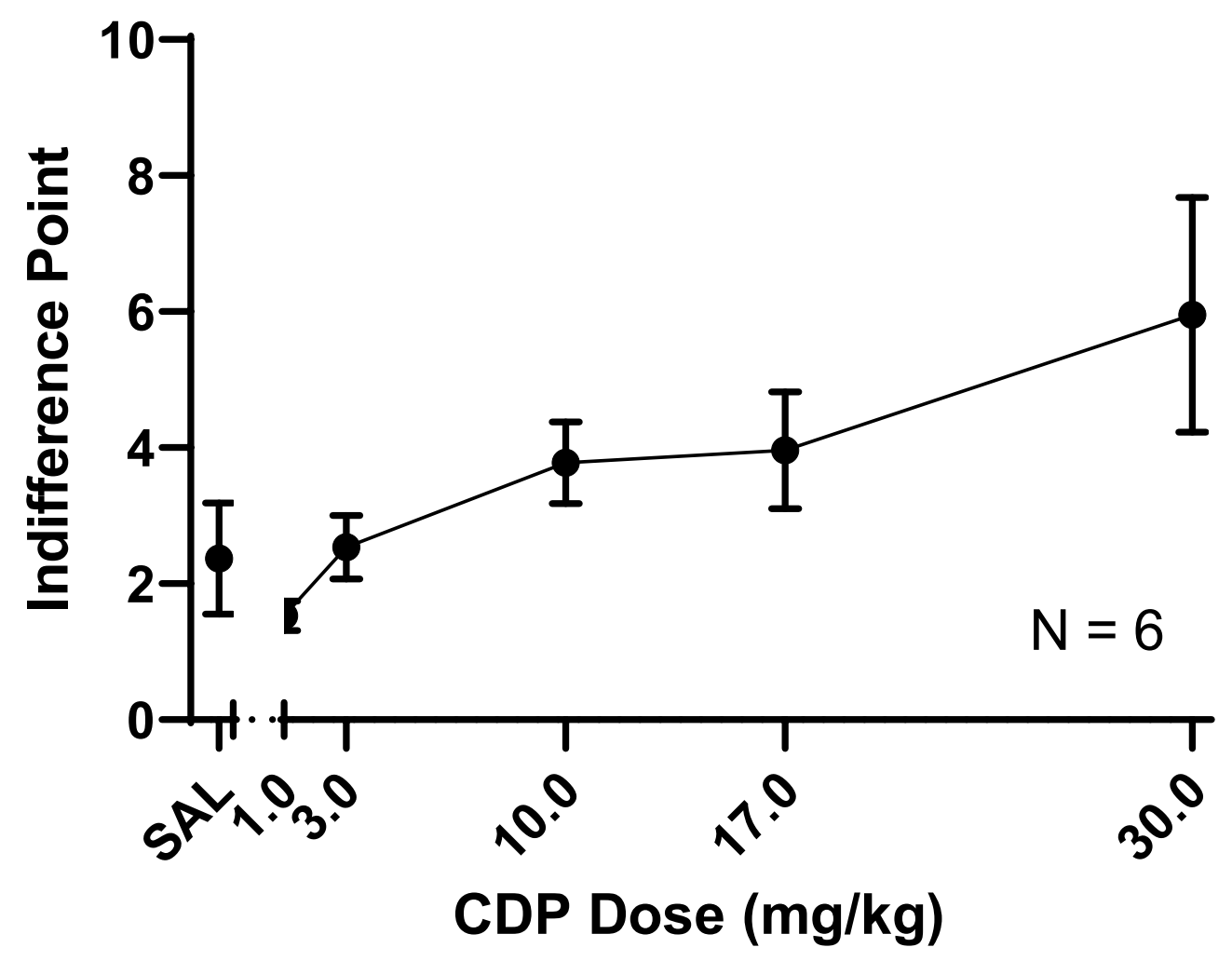

Note. Indifference points were higher relative to saline at the $30.0 \mathrm{mg} / \mathrm{kg}$ dose of CDP $(p=.04)$. 


\section{Figure 13}

Means and SEM for percent larger-reinforcer choice under saline during acute and chronic drug exposure.

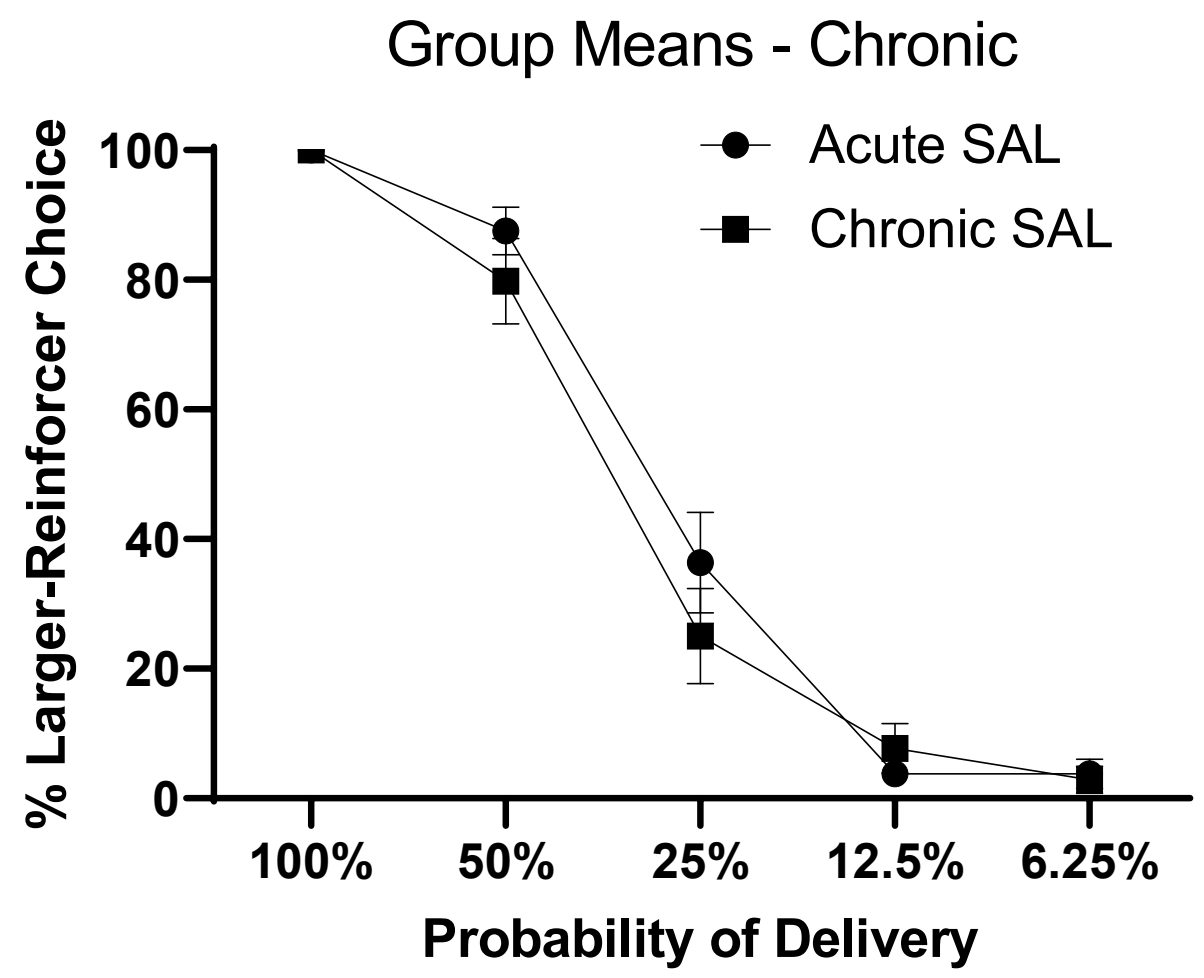




\section{Figure 14}

Means and SEM for overall (full session) percent larger-reinforcer choice as a function of dose during acute and chronic drug exposure.

\section{Dose-Response Function}

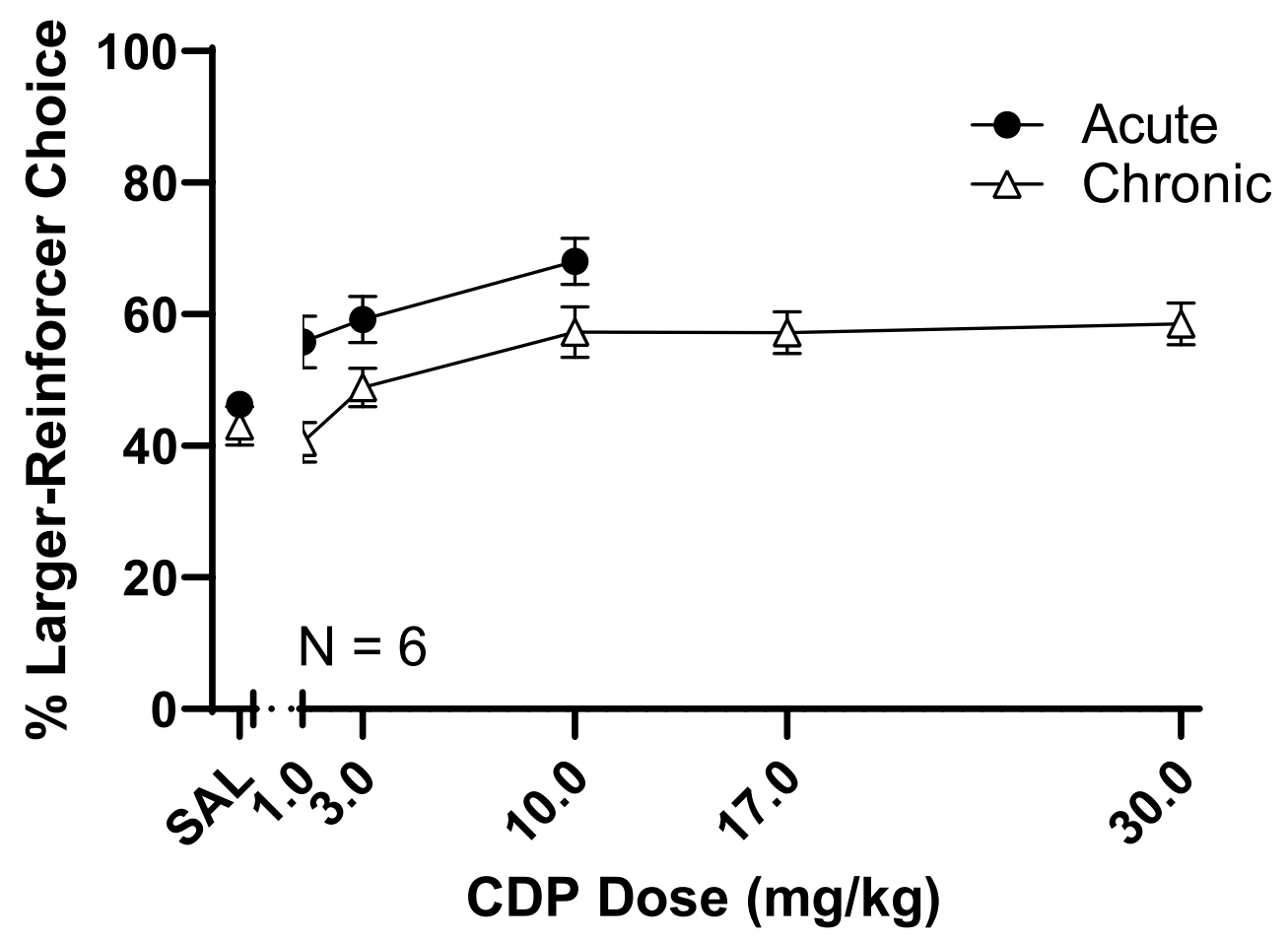

Note. The 17.0 and $30.0 \mathrm{mg} / \mathrm{kg}$ doses from the acute-exposure phase were excluded from analysis due to generalized response disruption. 